Article

\title{
Intelligent Colored Token Petri Nets for Modeling, Control, and Validation of Dynamic Changes in Reconfigurable Manufacturing Systems
}

\author{
Husam Kaid ${ }^{1, *(\mathbb{D})}$, Abdulrahman Al-Ahmari ${ }^{1, *}$, Zhiwu Li ${ }^{2,3}$ and Reggie Davidrajuh ${ }^{4}$ (i) \\ 1 Industrial Engineering Department, College of Engineering, King Saud University, \\ Riyadh 11421, Saudi Arabia \\ 2 Institute of Systems Engineering, Macau University of Science and Technology, Taipa, \\ Macau 999078, China; systemscontrol@gmail.com \\ 3 School of Electro-Mechanical Engineering, Xidian University, Xi' an 710071, China \\ 4 Faculty of Science and Technology, University of Stavanger, 4036 Stavanger, Norway; \\ reggie.davidrajuh@uis.no \\ * Correspondence: yemenhussam@yahoo.com (H.K.); alahmari@ksu.edu.sa (A.A.-A.)
}

Received: 19 February 2020; Accepted: 12 March 2020; Published: 20 March 2020

\begin{abstract}
The invention of reconfigurable manufacturing systems (RMSs) has created a challenging problem: how to quickly and effectively modify an RMS to address dynamic changes in a manufacturing system, such as processing failures and rework, machine breakdowns, addition of new machines, addition of new products, removal of old machines, and changes in processing routes induced by the competitive global market. This paper proposes a new model, the intelligent colored token Petri net (ICTPN), to simulate dynamic changes or reconfigurations of a system. The main idea is that intelligent colored tokens denote part types that represent real-time knowledge about changes and status of a system. Thus, dynamic configurations of a system can be effectively modeled. The developed ICTPN can model dynamic changes of a system in a modular manner, resulting in the development of a very compact model. In addition, when configurations appear, only the changed colored token of the part type from the current model has to be modified. Based on the resultant ICTPN model, deadlock-free, conservative, and reversible behavioral properties, among others, are guaranteed. The developed ICTPN model was tested and validated using the GPenSIM tool and compared with existing methods from the literature.
\end{abstract}

Keywords: Reconfigurable manufacturing system; colored Petri net; modeling; simulation

\section{Introduction}

A manufacturing system (MS) is a conglomeration of robots, machine tools, fixtures, and buffers. Several types of products enter the MS at separate points in time. The system can process these parts based on a specified sequence of operations and resource sharing. In the competitive global market, MSs must handle unpredictable and rapid market changes. To cope with these dynamic changes, MSs need to execute quick changes in their software and hardware. Nevertheless, traditional manufacturing systems cannot successfully meet this requirement because they need large capital investments. To tackle these drawbacks in traditional manufacturing systems, reconfigurable manufacturing systems (RMSs) were developed [1-3]. RMSs are a new class of manufacturing systems and are subject to dynamic and random configurations in real time. These changes include processing failures and rework, machine breakdowns, addition of new machines, addition of new products, removal of old machines, and changes in processing routes. 
To address the dynamic change problem in manufacturing systems, several approaches with Petri nets have been proposed. The study of Reference [4] presented a new higher-level deadlock control technique for the serial and parallel configuration of RMSs. RMSs have been used to replace traditional, large volume manufacturing systems, including dedicated production systems, providing more convertibility and flexibility. A rule-based matrix approach was developed and implemented in serial and parallel configurations. Higher-level deadlocks that are not prohibited by the existing approach were found through this type of application in the example RMS.

The study of Reference [5] introduced an improved net rewriting system (INRS)-based approach to automatically reconfigure an RMS supervisory controller based on Petri nets. Modifications to an RMS configuration were established into rules for rewriting that were then implemented in the original Petri net controller. First, the INRS was developed as the basis for reconfiguration. This can dynamically modify the structure of a Petri net model. Second, the study provided a triple representation of an RMS configuration and proposed an INRS-based approach to design a Petri net controller for an RMS. Finally, the article focused on providing an INRS-based approach for quick and automatic reconfiguration of this type of Petri net controller. In this approach, there is no verification or validation of the behavioral properties, i.e., reversibility, boundedness, and liveness for a reconfigured system.

A new Petri net model, called an intelligent token Petri net (ITPN), was presented by Reference [6]. In this model, tokens representing job types carry real-time knowledge about system changes and status, the same as intelligent cards in practice. An ITPN can model dynamic changes (adding new machines and products) in modular form, resulting in the development of a very compact model. If changes occur, only the changed part of the current model needs to be modified. To make an ITPN deadlock-free and reversible, a deadlock-free control policy was presented based on the ITPN model. In addition, when an ITPN is modified according to the system changes, the policy is still applicable to the modified model. Therefore, when an ITPN model is modified, the control policy need not be changed. However, the reconfiguration mechanism in ITPN needs to be further studied. Some of dynamic changes do not clearly define the modularity that may bring confusion to engineers in understanding and future redeveloping an RMS. Correctness of the system such as coherence of states before and after reconfiguration of the system is not considered. In addition, there is no mention of temporal constraints, which are of great significance in real-time systems.

The work of Reference [7] presented the reconfigurable finite-capacity Petri net (RFCPN) for the dynamic configuration of a flexible MS. An RFCPN is a Petri net extension that can be used for modeling, simulating, and validating simultaneous systems, which are subject to changes. Kahloul et al. [8] used reconfigurable object nets (RONs) to model, simulate, and analyze RMSs. The study proposed a formal approach to meet a new requirement (production of bricks used in slabs). A new extrusion machine (EMS) and a new cutting machine (CMS) were included in the configuration. The reconfiguration was defined as graph transformations, a simulation was performed using the RON tool, and software tools such as TINA-tool [9] and PIPE-tool [10] were used in the analysis.

The work of Reference [11] explored the principles of various methods and took the best practices from each one. Reconfiguration mechanisms were developed using Holonic and multiagent system approaches to enable the systematic detection of faults for a reconfigurable distributed production control system. The principle of service-oriented architecture was used to describe communication interfaces. Using Petri net models, hybrid top-down and bottom-up approaches were presented.

From the perspective of multiagent systems, a reconfigurable MS formal model (RMSFM) was developed in Reference [12], where two complementary formalisms (object-oriented Petri nets (ORPNs) and $\pi$-calculus) were used as formalisms. The ORPN was used to model both the initial structure and system behaviors of RMSs, while $\pi$-calculus was used to characterize the reconfiguration of RMSs. Petri Nets and $\pi$-calculus supporting tools were used to evaluate, check, and validate the RMSFM. $\pi$-calculus can analyze the reconfigurability mechanism and consistency of RMSs.

In the literature, several approaches with Petri nets were proposed to enhance dynamic change problems in MSs. However, most of them did not provide a reconfiguration mechanism or algorithm, 
could not ensure the PN's behavioral properties (i.e., boundedness, liveliness, and reversibility), or could not guarantee the correctness, accuracy, or validity of the reconfiguration results. The aim of this paper is to propose an intelligent colored token Petri net (ICTPN) based on a knowledge base for a rapid and valid reconfiguration-based Petri net for RMS. The main idea is to use colored tokens denoting part types that represent real-time knowledge about the changes and status of a system. The knowledge is introduced in the transitions, and the transitions know where the colored tokens should be located based on their colors and knowledge. The proposed ICTPN will cope with dynamic changes such as processing failures and rework, machine breakdowns, addition of new machines, addition of new products, removal of old machines, and change processing routes. The proposed ICTPN will ensure that the PN's behavioral properties, i.e., boundedness, liveliness, and reversibility, indicate that the modeled MS has finite states, is deadlock-free, and operates cyclically, respectively.

The proposed ICTPN can be implemented to Mass Customization Manufacturing (MCM) to solve its challenges, such as attempting to make the products available to customers in a timely manner, keeping high-quality production of a high variety of products, and achieving costs low to match those of standardized products. It can be introduced to the Lean Production (LP) concept, so that a company can apply an RMS to optimize the use of the part of resources for particular product families, and it can also decrease the waste induced by the part of an RMS's idle resources. It can be applied for Agile Manufacturing (AM) to increase rapid changeover between products, rapid introduction to new products and unattended operation. It can be implemented to Flexible Manufacturing System (FMS) to increase the speed of responsiveness to a variety of markets and customers. In addition, increasing the scalability to the required products volume and convertibility to the existing systems, machines, robots, and controls to match new production specifications.

The rest of the paper is organized as follows. Section 2 describes the ICTPN and synthesis. Section 3 explains how to model dynamic configurations by ICTPN. Section 4 describes the qualitative and quantitative properties of ICTPNs. Finally, Section 5 presents the conclusions and future research.

\section{Preliminary}

\subsection{Definition of Intelligent Colored Token Petri Nets}

Traditional Petri nets are popularly used to model, simulate, control, and analyze automated manufacturing systems (AMSs). Existing traditional Petri net studies assumed one or more of the following: (1) the system configuration is recognized and does not change throughout the operation, (2) there is no addition of new machines and no removal of old machines, and machine failures are not addressed, (3) rework is not required, and (4) products to be manufactured are identified, their process routes are specified, and the addition of new products is not applicable [13-32]. This means that traditional Petri net models do not undergo dynamic configurations, such as processing failures and rework, machine breakdowns, addition of new machines, addition of new products, removal of old machines, or change processing routes induced by the competitive global market. Therefore, an ICTPN based on a knowledge base for a rapid and valid reconfiguration-based Petri net for an RMS is proposed to deal with such dynamic changes. The main idea is that colored tokens denote part types that represent real-time knowledge about the changes and status of a system. Transitions know where the colored tokens should be located based on their colors and knowledge.

Definition 1. Let $N=\left(P_{A} \cup\left\{p_{o}\right\} \cup\left\{p_{r}\right\}, T, F, W, M_{0}, K\right)$ be a finite-capacity Petri net, where $p_{o}$ is a common load/unload place that represents a part type to be processed in the system, $p_{r}$ is a common transportation resource that represents transportation resources in the system, and $P_{A}=\left\{p_{1}, p_{2}, p_{2}, \ldots, p_{m}\right\}$ is a set of operation resources and $P_{A} \cap\left\{p_{r}\right\}=\emptyset$. T is a finite non-empty set of transitions. $F \subseteq(P \times T) \cup(T \times P)$ is said to be a set of directed arcs of $N$ that join the places to transitions or transitions to places, where $P=P_{A} \cup\left\{p_{o}\right\} \cup\left\{p_{r}\right\}$. $W:(P \times T) \cup(T \times P) \rightarrow I N$ is a mapping that assigns an arc's weight, where $I N=\{0,1,2, \ldots\} . M_{0}: P \rightarrow I N$ 
is an initial marking of N. K: $P \rightarrow I N$ is a capacity function where $K(p)$ represents the maximal number of tokens that place $p$ can hold at a time.

Definition 2. Let $\left(N, M_{o}\right)$ be a finite-capacity Petri net with $N=\left(P_{A} \cup\left\{p_{o}\right\} \cup\left\{p_{r}\right\}, T, F, W, M_{o}, K\right)$ and node $a \in P_{A} \cup\left\{p_{o}\right\} \cup\left\{p_{r}\right\} \cup T$. Then, $\bullet a=\left\{b \in P_{A} \cup\left\{p_{o}\right\} \cup\left\{p_{r}\right\} \cup T \mid(b, a) \in F\right\}$ is named the pre-set of node $a$, and $a \bullet=\left\{b \in P_{A} \cup\left\{p_{o}\right\} \cup\left\{p_{r}\right\} \cup T \mid(a, b) \in F\right\}$ is named the post-set of node $a$.

Definition 3. Let $\left(N, M_{0}\right)$ be a colored finite-capacity Petri net with $N=\left(P_{A} \cup\left\{p_{o}\right\} \cup\left\{p_{r}\right\}, T, F, W, M_{o}, K, S C\right.$, $\left.C_{f}, N_{f}, A_{f}, G_{f}, I_{f}\right)$, where $P_{A}, p_{o}, p_{r}, T, F, W, M_{o}$, and $K$ are defined in Definition 1. SC is a color set that contains colors $c_{i}$ and the operations on the colors. $C_{f}$ is the color function that maps $p_{i} \in P_{C}$ into colors $c_{i} \in S C . N_{f}$ is the node function that maps $F$ into $(P \times T) \cup(T \times P)$. $A_{f}$ is the arc function that maps each flow (arc) $f \in F$ into the term e. $G_{f}$ is the guard function that maps each transition $t_{i} \in T$ to a guard expression $g$ that has a Boolean value. $I_{f}$ is the initialization function that maps each place $p_{i} \in P_{C}$ into an initialization expression.

Definition 4. Let ICTPN be an intelligent colored token Petri net with $N=\left(P_{A} \cup\left\{p_{o}\right\} \cup\left\{p_{r}\right\}, T, F, W, M_{0}, K\right.$, $\left.\Psi\left(p, c_{p i}, c_{t i}, d\right)\right)$, where

1. Given $p \in P_{A}, M(p)$ is a marking of part type token with color as represented by $M(p)=\left\{c_{p i} \backslash c_{p i} \in T C\right\}$, where TC represent the set of tokens with colors representing set of part types.

2. Given $p=p_{r}, M(p)$ is a marking of transportation resource token with color as represented by $M(p)=\left\{c_{t i} \backslash c_{t i} \in R C\right\}$, where $R C$ represent the set of colors of transportation resources types.

3. Given $p \in P_{A} \cup\left\{p_{r}\right\}, c_{p i} \in T C$, and $c_{t i} \in R C, \Psi\left(p, c_{p i}, c_{t i}, d\right)$ is a knowledge function mapping tokens types $c_{p i}$ and $c_{t i}$ in place $p$ at time d to a transition $t$, in which $c_{p i}$ and $c_{t i}$ can be used to enable $t$, as represented by $\Psi\left(p, c_{p i}, c_{t i}, d\right)=\{t \backslash t \in T\}$.

Definition 5. Let $N=\left(P_{A} \cup\left\{p_{o}\right\} \cup\left\{p_{r}\right\}, T, F, W, M_{o}, K, \Psi\left(p, c_{p i}, c_{t i}, d\right)\right)$ be an ICTPN. An ICTPN with a marking is said to be acceptably marked if the following conditions are satisfied: (1) $M_{o}\left(p_{o}\right) \geq 1,(2) M_{o}\left(p_{r}\right) \geq 1$, and (3) $M_{o}(p)=0, \forall p \in P_{A}$.

Definition 6. Let ICTPN be an intelligent colored token Petri net with $N=\left(P_{A} \cup\left\{p_{o}\right\} \cup\left\{p_{r}\right\}, T, F, W\right.$, $\left.M_{o}, K, \Psi\left(p, c_{p i}, c_{t i}, d\right)\right)$. A transition $t \in T$ is enabled at marking $M$ if the following conditions are satisfied: $\forall p \in \bullet \bullet \cap\left(P_{A} \cup\left\{p_{r}\right\}\right), \exists c_{p i} \in M\left(\bullet t \cap P_{A}\right), \exists c_{t i} \in M\left(\bullet t \cap\left\{p_{r}\right\}\right), t \in \Psi\left(p, c_{p i}, c_{t i}, d\right), M\left(t^{\bullet} \cap P_{A}\right)-\left\{c_{p i}\right\}$ $<K\left(t^{\bullet} \cap P_{A}\right)$, and $M\left(t^{\bullet} \cap\left\{p_{r}\right\}\right)-\left\{c_{p i}\right\}<K\left(t^{\bullet} \cap\left\{p_{r}\right\}\right)$.

Definition 7. Let ICTPN be an intelligent colored token Petri net with $N=\left(P_{A} \cup\left\{p_{o}\right\} \cup\left\{p_{r}\right\}, T, F, W, M_{0}, K\right.$, $\left.\Psi\left(p, c_{p i}, c_{t i}, d\right)\right)$. N has a self-loop if for all $a, b \in P_{A} \cup\left\{p_{o}\right\} \cup\left\{p_{r}\right\} \cup T, W(a, b)>0$ implies $W(b, a)>0$.

Definition 8. Let ICTPN be an intelligent colored token Petri net with $N=\left(P_{A} \cup\left\{p_{o}\right\} \cup\left\{p_{r}\right\}, T, F, W, M_{0}, K\right.$, $\left.\Psi\left(p, c_{p i}, c_{t i}, d\right)\right)$. $N$ is self-loop free if for all $a, b \in P_{A} \cup\left\{p_{o}\right\} \cup\left\{p_{r}\right\} \cup T, W(a, b)>0$ implies $W(b, a)=0$.

Definition 9. Let ICTPN be an intelligent colored token Petri net with $N=\left(P_{A} \cup\left\{p_{o}\right\} \cup\left\{p_{r}\right\}, T, F, M_{o}, K\right.$, $\Psi\left(p, c_{p i}, c_{t i}, d\right)$ ). A transition $t \in T$ that is enabled at marking $M$ by $c_{p i}$ and $c_{t i}$ may fire. The marking of the ICTPN can be changed from $M$ to $M^{\prime}$ as follows:

$$
M^{\prime}(p)=\left[\begin{array}{ll}
M(p)-\left\{c_{p i}\right\} & \text { if } p \in \bullet \cap \cap P_{A} \\
M(p)+\left\{c_{p i}\right\} & \text { if } p \in t^{\bullet} \cap P_{A} \\
M(p)-\left\{c_{t i}\right\} & \text { if } p \in \bullet \cap\left\{p_{r}\right\} \\
M(p)-\left\{c_{t i}\right\} & \text { if } p \in t^{\bullet} \cap\left\{p_{r}\right\} \\
M(p) & \text { Otherwise }
\end{array}\right]
$$


Definition 10. Let ICTPN be an intelligent colored token Petri net with $N=\left(P_{A} \cup\left\{p_{o}\right\} \cup\left\{p_{r}\right\}, T, F, W, M_{o}, K\right.$, $\left.\Psi\left(p, c_{p i}, c_{t i}, d\right)\right) . N$ is known as an ordinary net if $\forall(p, t) \in F, W(p, t)=1$, where $N=(P, T, F)$. $N$ is named a weighted net if there is an arc between $x$ and $y$ such that $W(x, y)>1$.

Definition 11. Let ICTPN be an intelligent colored token Petri net with $N=\left(P_{A} \cup\left\{p_{o}\right\} \cup\left\{p_{r}\right\}, T, F, W, M_{o}, K\right.$, $\left.\Psi\left(p, c_{p i}, c_{t i}, d\right)\right)$. The set of markings that are reachable from $M$ in $N$ is named the set of reachability of the Petri net model $(N, M)$, denoted by $R(N, M)$. A transition $t \in T$ is live if for all $M \in R(N, M)$, there exists a reachable marking $M^{\prime} \in R(N, M)$ such that $M^{\prime}[t\rangle$ holds. A net system $\left(N, M_{0}\right)$ is dead at $M_{0}$ if there does not exist $t \in T$ such that $M_{0}[t\rangle$ holds.

Definition 12. Let ICTPN be an intelligent colored token Petri net with $N=\left(P_{A} \cup\left\{p_{o}\right\} \cup\left\{p_{r}\right\}, T, F, W, M_{0}, K\right.$, $\left.\Psi\left(p, c_{p i}, c_{t i}, d\right)\right)$. A marking $M_{o}$ is a reversible if, for each marking $M^{\prime} \in R\left(N, M_{o}\right), M_{o}$ is reachable from $M^{\prime}$.

Definition 13. Let ICTPN be an intelligent colored token Petri net with $N=\left(P_{A} \cup\left\{p_{o}\right\} \cup\left\{p_{r}\right\}, T, F, W, M_{o}, K\right.$, $\left.\Psi\left(p, c_{p i}, c_{t i}, d\right)\right)$. A marking $M^{\prime}$ is a coverable if there exists a marking $M^{\prime \prime} \in R\left(N, M_{o}\right)$ such that $M^{\prime \prime}(p) \geq M^{\prime}(p)$ for each $p$ in the $N$.

Definition 14. Let ICTPN be an intelligent colored token Petri net with $N=\left(P_{A} \cup\left\{p_{o}\right\} \cup\left\{p_{r}\right\}, T, F, W, M_{o}, K\right.$, $\left.\Psi\left(p, c_{p i}, c_{t i}, d\right)\right)$. [N] is said to be the incidence matrix of net $N$, where [N] is an integer matrix that consists of $|T|$ columns and $|P|$ rows with $[N](p, t)=W(t, p)-W(p, t)$.

Definition 15. Let ICTPN be an intelligent colored token Petri nets with $N=\left(P_{A} \cup\left\{p_{o}\right\} \cup\left\{p_{r}\right\}, T, F, W, M_{o}, K\right.$, $\left.\Psi\left(p, c_{p i}, c_{t i}, d\right)\right)$. A marking $M^{\prime}$ is said to be reachable from $M$ if there exist a finite transition sequence $\delta=t_{1} t_{2}$ $t_{3} \ldots t_{n}$ that can be fired, and markings $M_{1}, M_{2}, M_{3}, \ldots$, and $M_{n-1}$ such that $M\left[t_{1}\right\rangle M_{1}\left[t_{2}\right\rangle M_{2}\left[t_{3}\right\rangle M_{2} \ldots$ $M_{n-1}\left[t_{n}\right\rangle M^{\prime}$, denoted as $M[\delta\rangle M^{\prime}$, satisfies the state equation $M^{\prime}=M+[N] \vec{\delta}$, where $\vec{\delta}: T \rightarrow I N$ maps $t$ in $T$ to the number of appearances of $t$ in $\delta$ and is called a Parikh vector or a firing count vector.

\subsection{Design of Intelligent Colored Token Petri Nets}

In AMS, let $O R=\left\{O R_{1}, O R_{2}, O R_{3}, \ldots, O R_{n}\right\}$ be all possible routes and should be manufactured in a system for all types of parts $P T$, where $O R_{i}$ is $R_{o} \rightarrow R_{i 1} \rightarrow R_{i 2} \rightarrow \ldots \ldots \rightarrow R_{i F i} \rightarrow R_{o}, n, F_{i}$ are large integer numbers, $R_{o}$ denotes a load/unload station of the system with infinite capacity, and $R_{i}(i \neq 0)$ may be a buffer or machine, which is named an operation resource. An operation route starts from $R_{o}$ and ends at $R_{0}$. For each part, if there exists more than one operation route such that $R_{i} \rightarrow R_{j(i \neq j)}$, it is said that there is a path from $R_{i}$ to $R_{j}$. When a part transfers from $R_{i}$ to $R_{j}$, namely it is transported by a material handling device, such as an AGV or robot that is named a transportation resource.

In Definition $4, \Psi\left(p, c_{p i}, c_{t i}, d\right)$ knows where colored tokens $c_{p i}$ and $c_{t i}$ should go based on their colors and knowledge and knows the system configuration and the state of the tokens themselves. Because of this, $c_{p i}$ and $c_{t i}$ are named intelligent colored tokens. An approach can be used to synthesize the ICTPN irrespective of how complicated the system operation routes are.

According to part routing information and transportation requirements, the modeling of operation and transportation resources is stated as follows: 


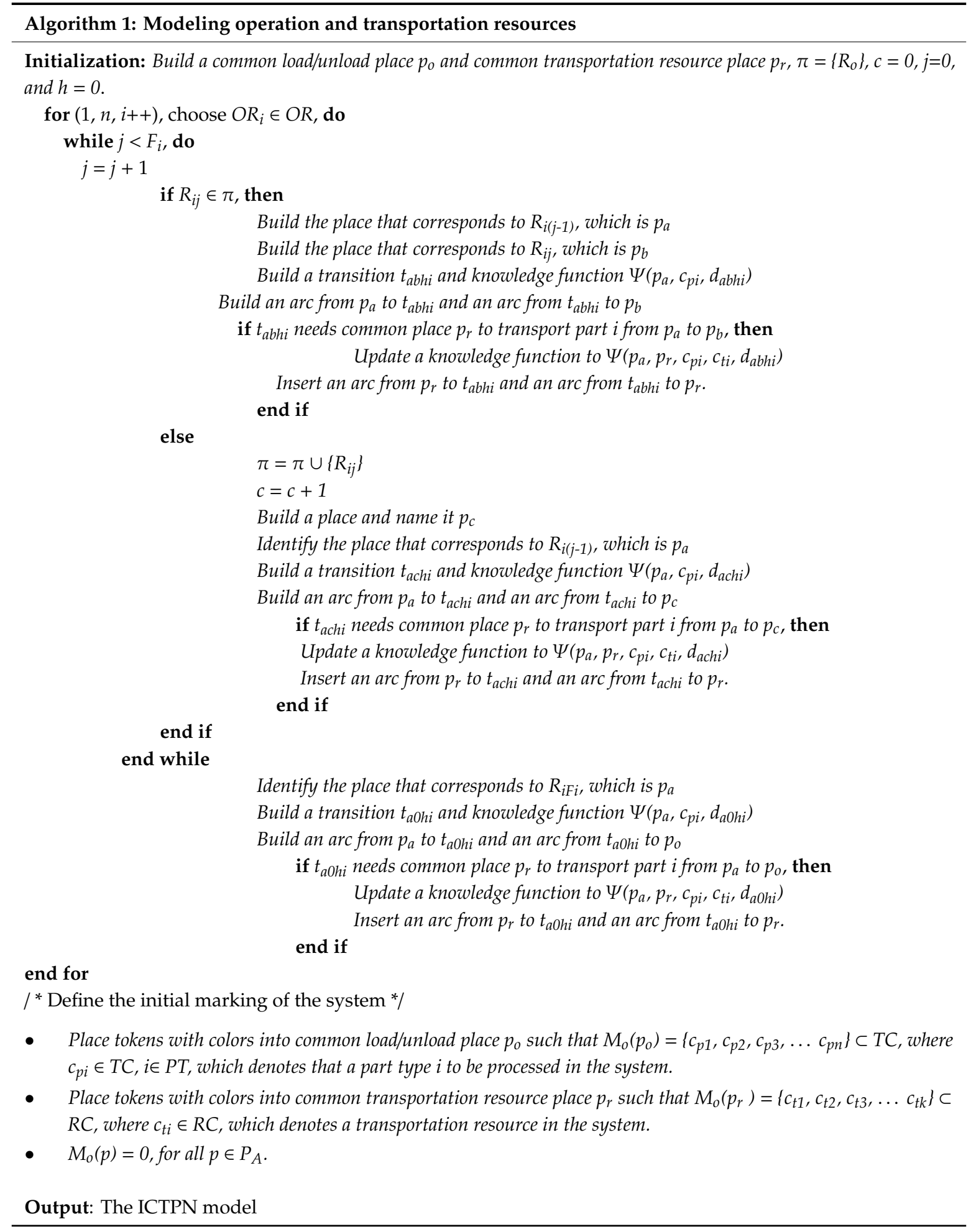

To demonstrate the synthesis of an ICTPN, consider an AMS example, shown in Figure 1a. The AMS Petri net model is given in Chen et al. [33], Piroddi et al. [34], Chen and Li [35], Chen et al. [36], and Kaid et al. [37]. The system is composed of four machines $\left(M_{1}, M_{2}, M_{3}\right.$ and $M_{4}$; each machine can process one part at a time) and two robots $\left(R o_{1}\right.$ and $R o_{2}$; each robot can hold a part at a time). There is a loading/unloading buffer. Two part-types, $\mathrm{A}$ and $\mathrm{B}$, are considered to be processed in the system. The operations sequences of these two part-types are shown in Figure 1b. The operation and transportation resources model is shown in Figure 2, for operation resources, $p_{1}, p_{2}, p_{3}$, and $p_{4}$ model $M_{1}, M_{2}, M_{3}$, and $M_{4}$, respectively. The process route of Part A is constructed by $p_{0} \rightarrow t_{011 A} \rightarrow p_{1}$ 
$\rightarrow t_{130 \mathrm{~A}} \rightarrow p_{3} \rightarrow t_{300 \mathrm{~A}} \rightarrow p_{0}$, or $p_{0} \rightarrow t_{022 \mathrm{~A}} \rightarrow p_{2} \rightarrow t_{230 \mathrm{~A}} \rightarrow p_{3} \rightarrow t_{300 \mathrm{~A}} \rightarrow p_{0}$. The process route of Part $\mathrm{B}$ is constructed by $p_{0} \rightarrow t_{040 \mathrm{~B}} \rightarrow p_{4} \rightarrow t_{420 \mathrm{~B}} \rightarrow p_{2} \rightarrow t_{200 \mathrm{~B}} \rightarrow p_{0}$, for transportation resources, common place $p_{r}$ models $R o_{1}$ and $R o_{2}$.

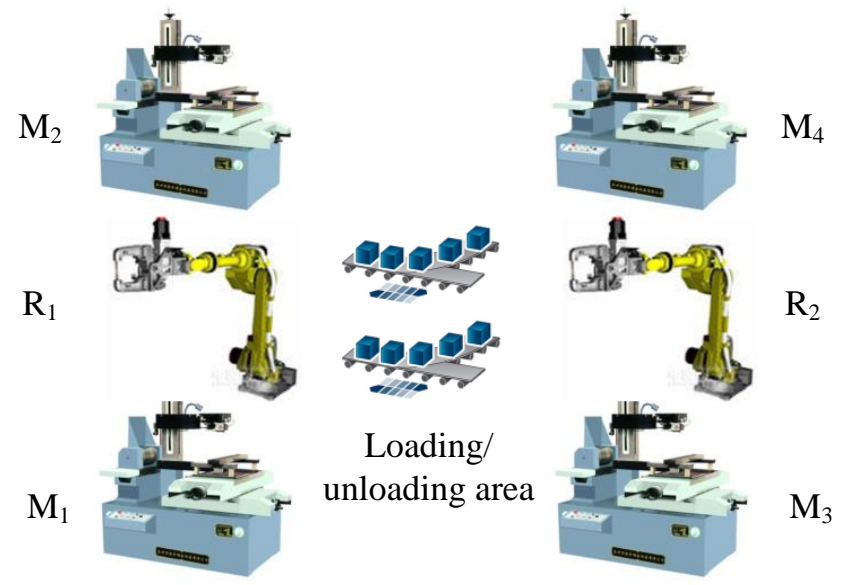

(a)

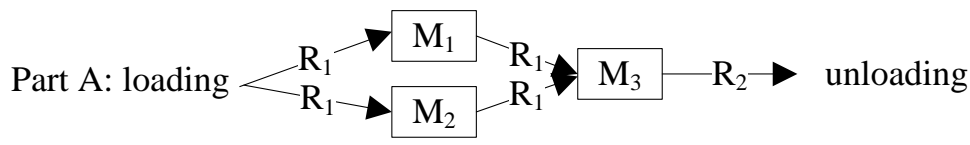

Part B: loading $\longrightarrow \mathrm{R}_{2} \rightarrow \mathrm{M}_{4}-\mathrm{R}_{1} \rightarrow \mathrm{M}_{2} \rightarrow \mathrm{R}_{1} \rightarrow$ unloading

(b)

Figure 1. (a) An AMS example, (b) Production sequence.

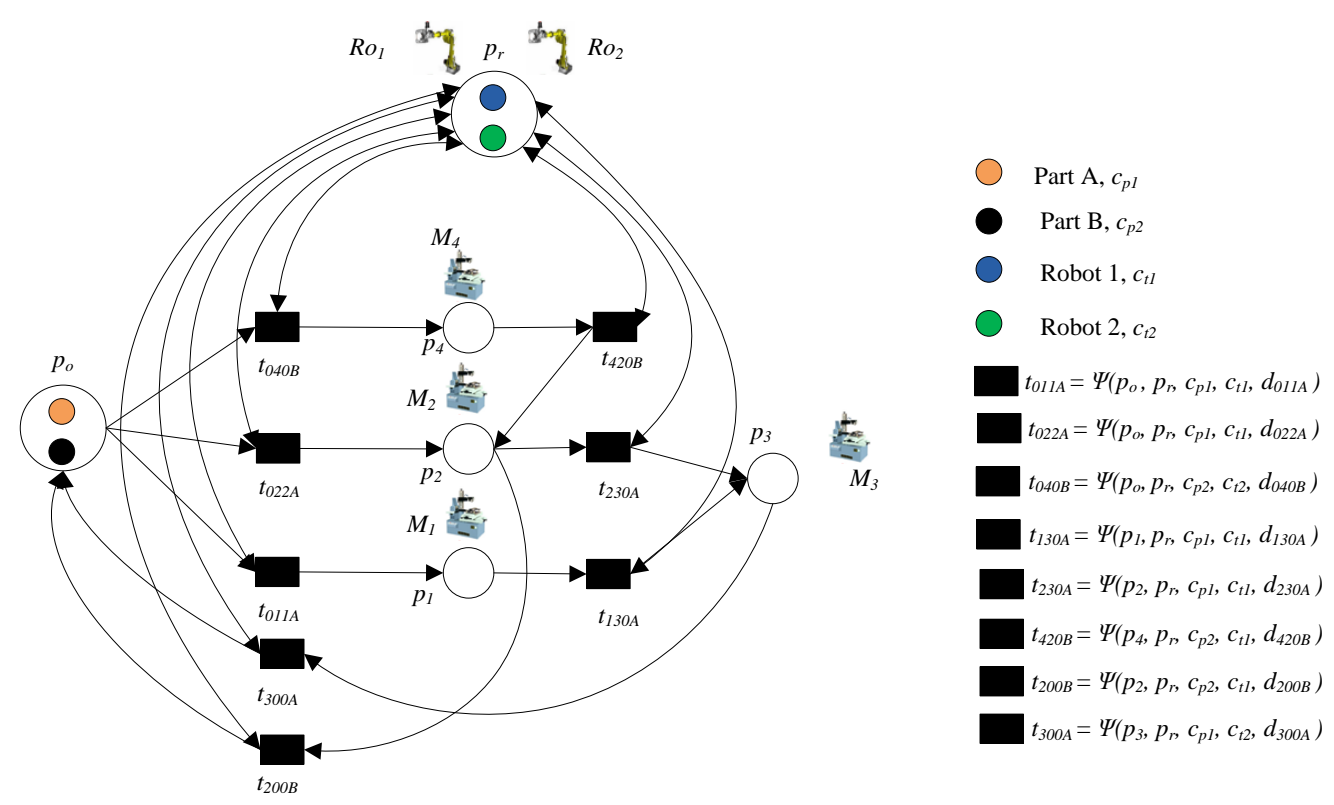

Figure 2. Intelligent colored token Petri net (ICTPN) of an AMS example, as shown in Figure 1a.

To model the transportation operations of part types, transition $t_{011 A}$ denotes loading part $\mathrm{A}$ to $p_{1}$ and transition $t_{022 A}$ denotes loading part $\mathrm{A}$ to $p_{2}$, where $R o_{1}$ is needed. Transition $t_{300 A}$ denotes unloading part $\mathrm{A}$ from $p_{3}$, where $\mathrm{Ro}_{2}$ is needed. Transitions $t_{040 \mathrm{~B}}$ denotes loading part $\mathrm{B}$ to $p_{4}$, where $\mathrm{Ro}_{2}$ is needed, and transition $t_{200 \mathrm{~B}}$ denotes unloading part $\mathrm{B}$ from $p_{2}$, where $R o_{1}$ is needed. These operations can be done by developed common place $p_{r}$. Thus, common place $p_{r}$ and arcs $\left(p_{r}, t_{011 A}\right)$, 
$\left(t_{011 A}, p_{r}\right),\left(p_{r}, t_{022 A}\right),\left(t_{022 A}, p_{r}\right),\left(p_{r}, t_{300 A}\right),\left(t_{300 A}, p_{r}\right),\left(p_{r}, t_{040 B}\right),\left(t_{040 B}, p_{r}\right),\left(p_{r}, t_{200 B}\right)$, and $\left(t_{200 B}, p_{r}\right)$ are inserted into the model. Transporting part A between $p_{1}$ and $p_{3}\left(R o_{1}\right.$ is needed) or $p_{2}$ and $p_{3}\left(R o_{1}\right.$ is needed) is represented by transitions $t_{130 A}$ or $t_{230 A}$, respectively. Transporting part B between $p_{4}$ and $p_{2}\left(R o_{1}\right.$ is needed $)$ is represented by transitions $t_{420 B}$. Thus, common place $p_{r}$ and arcs $\left(p_{r}, t_{130 A}\right),\left(t_{130 A}\right.$, $\left.p_{r}\right),\left(p_{r}, t_{230 A}\right),\left(t_{230 A}, p_{r}\right),\left(p_{r}, t_{420 B}\right)$, and $\left(t_{420 B}, p_{r}\right)$ are inserted into the model.

Note that in ICTPN, transition $t$ has one input place from $p \in P_{A}$, one input place from $p_{r}$, one output place to $p \in P_{A}$, and one output place to $p_{r}$. Next, to define the initial marking of the system, place tokens with colors into place $p_{o}$ such that $M_{o}\left(p_{o}\right)=\left\{c_{p 1}, c_{p 2}\right\}$, where $c_{p 1}$ and $c_{p 2}$ denote a part type $\mathrm{A}$ and part type $\mathrm{B}$, respectively. Place tokens with colors into place $p_{r}$ such that $M_{o}\left(p_{r}\right)=\left\{c_{t 1}, c_{t 2}\right\}$, where $c_{t 1}$ and $c_{t 2}$ denote transportation resources in the system $R o_{1}$ and $R o_{2}$, respectively.

Consider the ICTPN model shown in Figure 2. If the condition given in Definition 6 is satisfied, then we can say that $t$ is enabled by $c_{p i}$ and $c_{t i}$. By Definition 9, the marking of the ICTPN can be changed as follows. When transition $t_{011 A}\left(\Psi\left(p_{0}, p_{r}, c_{p 1}, c_{t 1}, d_{011 A}\right)\right)$ fires for duration $d_{011 A}$, it selects only one token with color $c_{p 1}$ from input place $p_{\mathrm{o}}$ and one token with color $c_{t 1}$ from input place $p_{\mathrm{r}}$. If $t_{011 A}$ fires, then it transfers only one token with color $c_{p 1}$ to output place $p_{1}$ and one token with color $c_{t 1}$ to output place $p_{\mathrm{r}}$. When transition $t_{022 A}\left(\Psi\left(p_{0}, p_{r}, c_{p 1}, c_{t 1}, d_{022 A}\right)\right)$ fires for duration $d_{022 A}$, then it selects only one token with color $c_{p 1}$ from input place $p_{\mathrm{o}}$ and one token with color $c_{t 1}$ from input place $p_{\mathrm{r}}$. If $t_{022 A}$ fires, it transfers only one token with color $c_{p 1}$ to output place $p_{2}$ and one token with color $c_{t 1}$ to output place $p_{\mathrm{r}}$. When transition $t_{040 B}\left(\Psi\left(p_{0}, p_{r}, c_{p 2}, c_{t 2}, d_{040 B}\right)\right)$ fires for duration $d_{040 B}$, then it selects only one token with color $c_{p 2}$ from input place $p_{\mathrm{o}}$ and one token with color $c_{t 2}$ from input place $p_{\mathrm{r}}$. If $t_{040 B}$ fires, it transfers only one token with color $c_{p 2}$ to output place $p_{4}$ and one token with color $c_{t 2}$ to output place $p_{\mathrm{r}}$. In addition, if transition $t_{130 A}\left(\Psi\left(p_{1}, p_{r}, c_{p 1}, c_{t 1}, d_{130 A}\right)\right)$ fires for duration $d_{130 A}$, it selects only one token with color $c_{p 1}$ from input place $p_{1}$ and one token with color $c_{t 1}$ from input place $p_{\mathrm{r}}$. If $t_{130 \mathrm{~A}}$ fires, it transfers only one token with color $c_{p 1}$ to output place $p_{3}$ and one token with color $c_{t 1}$ to output place $p_{\mathrm{r}}$. Moreover, when transition $t_{230 A}\left(\Psi\left(p_{2}, p_{r}, c_{p 1}, c_{t 1}, d_{230 A}\right)\right)$ fires for duration $d_{230 A}$, it selects only one token with color $c_{p 1}$ from input place $p_{2}$ and one token with color $c_{t 1}$ from input place $p_{\mathrm{r}}$. If $t_{230 \mathrm{~A}}$ fired, it transfers only one token with color $c_{p 1}$ to output place $p_{3}$ and one token with color $c_{t 1}$ to output place $p_{\mathrm{r}}$. If transition $t_{420 B}\left(\Psi\left(p_{4}, p_{r}, c_{p 2}, c_{t 1}, d_{420 B}\right)\right)$ fires for duration $d_{420 B}$, it selects only one token with color $c_{p 2}$ from input place $p_{4}$ and one token with color $c_{t 1}$ from input place $p_{\mathrm{r}}$. If $t_{420 B}$ fires, it transfers only one token with color $c_{p 2}$ to output place $p_{2}$ and one token with color $c_{t 1}$ to output place $p_{\mathrm{r}}$. Then, when transition $t_{200 B}\left(\Psi\left(p_{2}, p_{r}, c_{p 2}, c_{t 1}, d_{200 B}\right)\right)$ fires for duration $d_{200 B}$, it selects only one token with color $c_{p 2}$ from input place $p_{2}$ and one token with color $c_{t 1}$ from input place $p_{\mathrm{r}}$. If $t_{200 B}$ fires, it transfers only one token with color $c_{p 2}$ to output place $p_{\mathrm{o}}$ and one token with color $c_{t 1}$ to output place $p_{\mathrm{r}}$. Finally, if transition $t_{300 A}\left(\Psi\left(p_{3}, p_{r}, c_{p 1}, c_{t 2}, d_{300 A}\right)\right)$ fires for duration $d_{300 A}$, it selects only one token with color $c_{p 1}$ from input place $p_{3}$ and one token with color $c_{t 2}$ from input place $p_{\mathrm{r}}$. If $t_{300 \mathrm{~A}}$ fires, it transfers only one token with color $c_{p 1}$ to output place $p_{\mathrm{o}}$ and one token with color $c_{t 2}$ to output place $p_{\mathrm{r}}$.

\section{RMS Configuration Changes Modeling Based on ICTPN}

\subsection{Machine Breakdowns}

In an automated manufacturing system, the breakdown of its machines is usually caused by quality out-of-control signals, missing or defective part programs or tools, damaged tools, or the failure of sensing and actuating systems. For example, if a machine breakdown is detected, the operations that use the broken machine need to be performed by another machine. In this case, some processing routes are changed, which implies a modification to the structure of its Petri net model. Reconsider the ICTPN model shown in Figure 2. There are four machine tools, denoted by $p_{1}, p_{2}, p_{3}$, and $p_{4}$. Assume that $p_{1}$ is down and $p_{4}$ will perform the operations that were previously performed by itself and performed by $p_{1}$. Therefore, the structure of the ICTPN model is changed and will be re-designed such that the 
system with the removal of resource $p_{1}$ can operate continuously without stoppage. Hence, to model the reconfigured system, consider the following procedures:

Step 1: Disable the transitions connected to the place corresponding to the breakdown machine and remove or disable this place $p_{1}$.

Step 2: Change the names of transitions based on new machine $p_{4}$

Step 3: Change the operation route from $p_{0} \rightarrow t_{011 \mathrm{~A}} \rightarrow p_{1} \rightarrow t_{130 \mathrm{~A}} \rightarrow p_{3} \rightarrow t_{300 \mathrm{~A}} \rightarrow p_{0}$ to $p_{0} \rightarrow t_{041 \mathrm{~A}}$ $\rightarrow p_{4} \rightarrow t_{430 \mathrm{~A}} \rightarrow p_{3} \rightarrow t_{300 \mathrm{~A}} \rightarrow p_{0}$.

Step 4: Connect the transitions to the new machine $p_{4}$.

Step 5: Change the names of the knowledge function of transitions based on new machine $p_{4}$.

$$
\begin{aligned}
& t_{041 A}=\Psi\left(p_{0}, p_{r}, c_{p 1}, c_{t 1}, d_{041 A}\right) \\
& t_{430 A}=\Psi\left(p_{4}, p_{r}, c_{p 1}, c_{t 1}, d_{430 A}\right)
\end{aligned}
$$

An ICTPN for the reconfigured system by machine breakdowns is shown in Figure 3.

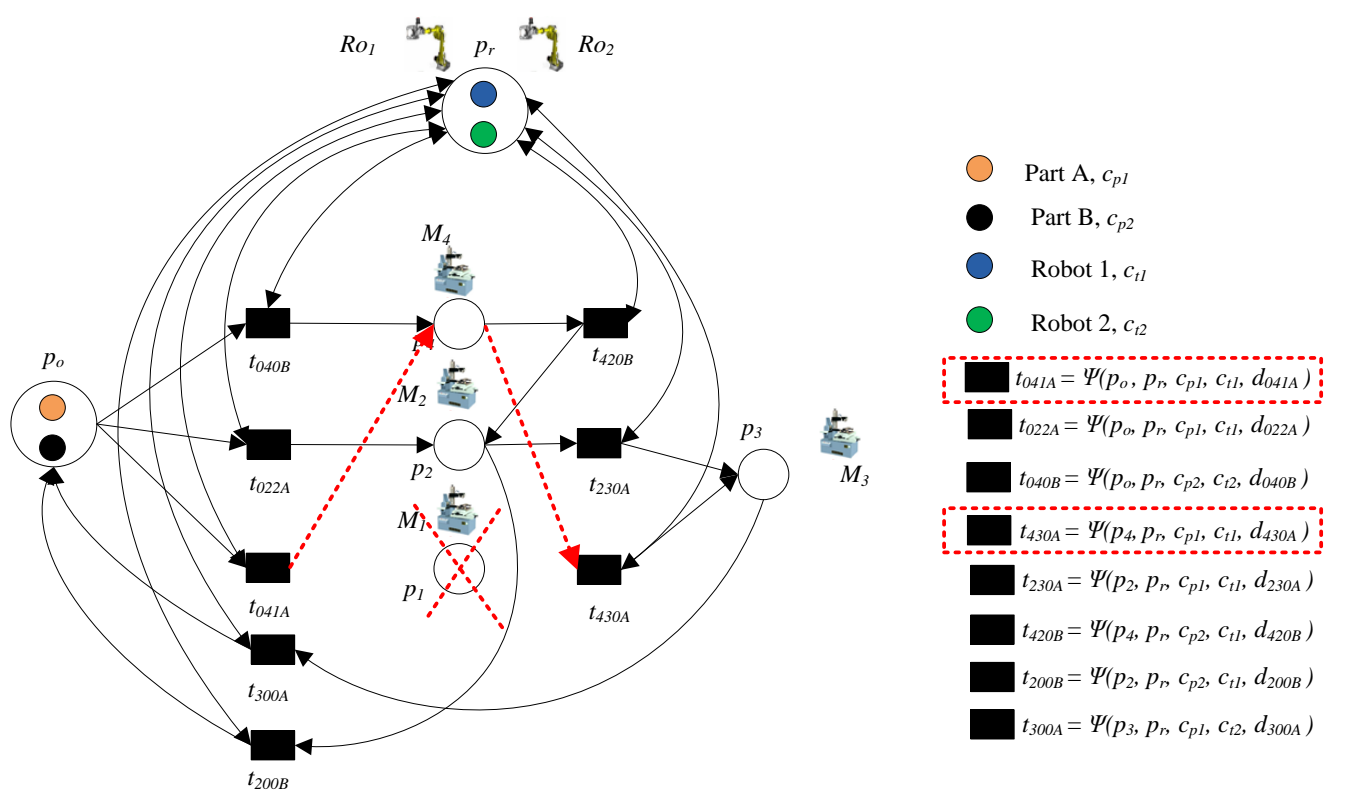

Figure 3. An ICTPN for the reconfigured system by machine breakdowns.

\subsection{Addition of New Product}

The second automated manufacturing system reconfiguration involves the addition of a new product. When a new product is added to a system, it means that a new route is added, which implies a modification to the structure of its Petri net model. To model the newly added route by using the ICTPN synthesis procedure, reconsider the ICTPN model shown in Figure 2. Assume that a new product part $C$ is added. It processing route is constructed by load/unload station $\rightarrow M_{4} \rightarrow M_{3}$ $\rightarrow$ load/unload station. To transport part $C$ between the load/unload station and $M_{4}, R o_{2}$ is needed, and to transport part $C$ between $M_{4}$ and $M_{3}, R o_{1}$ is needed. Hence, to model the reconfigured system, consider the following procedures:

Step 1: Add a new operation route from $p_{0} \rightarrow t_{040 C} \rightarrow p_{4} \rightarrow t_{430 \mathrm{C}} \rightarrow p_{3} \rightarrow t_{300 \mathrm{C}} \rightarrow p_{0}$.

Step 2: Add the transportation operation of part $C$. Transition $t_{040 C}$ denotes loading part $C$ to $p_{4}$, and $\mathrm{Ro}_{2}$ is needed; $t_{430 \mathrm{C}}$ denotes transporting part $\mathrm{C}$ to $p_{3}$ and $R o_{1}$ is needed. Transition $t_{300 C}$ denotes unloading part $C$ from $p_{3}$ and $R_{2}$ is needed. These operations can be done by common place $p_{r}$.

Step 3: Add the knowledge function of transitions based on a new operation route. 


$$
\begin{aligned}
& t_{040 \mathrm{C}}=\Psi\left(p_{0}, p_{r}, c_{p 3}, c_{t 2}, d_{040 \mathrm{C}}\right) \\
& t_{430 \mathrm{C}}=\Psi\left(p_{4}, p_{r}, c_{p 3}, c_{t 1}, d_{430 \mathrm{C}}\right) \\
& t_{300 \mathrm{C}}=\Psi\left(p_{3}, p_{r}, c_{p 3}, c_{t 2}, d_{300 \mathrm{C}}\right) .
\end{aligned}
$$

Step 4: Place the token with color $c_{p 3}$ into place $p_{0}$, which denotes a part $C$ that will be processed in the system.

An ICTPN for the reconfigured system by the addition of a new product is shown in Figure 4 .
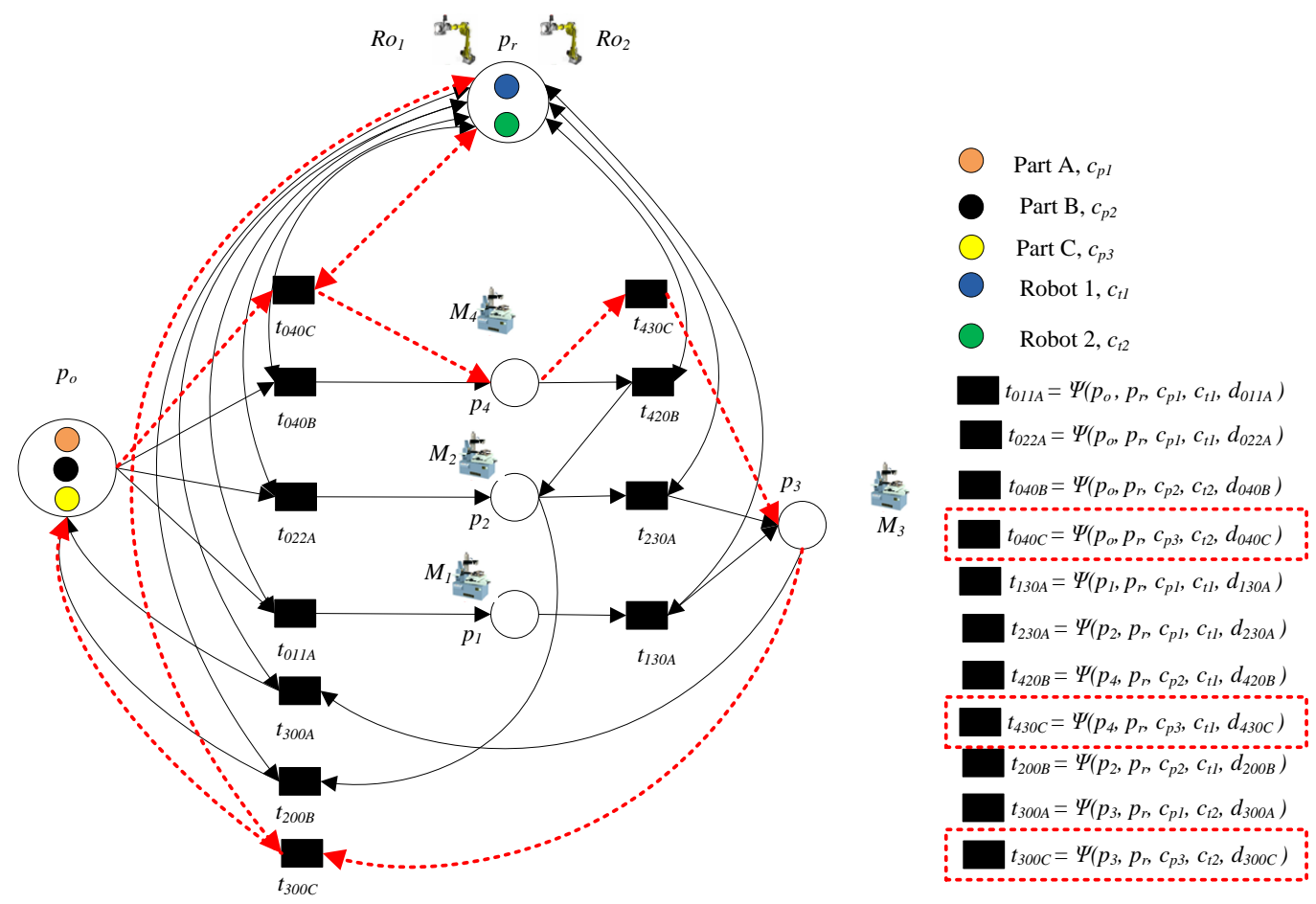

Figure 4. An ICTPN for the reconfigured system by addition of a new product.

\subsection{Addition of New Machine}

The third system reconfiguration includes the addition of a new machine. In this case, a new machine is added to the system. Operations for new or used parts are conducted by the newly added machine. Moreover, new job processing routes can be generated, which implies the modification of the structure of the Petri net model. To model the newly added machine by using the ICTPN synthesis procedure, new places and transitions can be added based on the original ICTPN.

Consider the ICTPN model shown in Figure 2. Assume that a new machine $M_{5}$ is added to process part $\mathrm{B}$. The processing route of part $\mathrm{B}$ is constructed by load/unload station $\rightarrow M_{4}$ or $M_{5}$ $\rightarrow M_{2} \rightarrow$ load/unload station. To transport part B between the load/unload station and $M_{4}$ or $M_{5}, R o_{2}$ is needed, and to transport part B between $M_{4}$ or $M_{5}$ and $M_{2}, R o_{1}$ is needed. Hence, to model the reconfigured system, consider the following procedures:

Step 1: Add process routes of part B as route 1: $p_{0} \rightarrow t_{041 B} \rightarrow p_{4} \rightarrow t_{420 B} \rightarrow p_{2} \rightarrow t_{200 B} \rightarrow p_{0}$, or route 2: $p_{0} \rightarrow t_{052 B} \rightarrow p_{5} \rightarrow t_{520 B} \rightarrow p_{2} \rightarrow t_{200 B} \rightarrow p_{0}$

Step 2: Add the transportation operation of part B. Transitions $t_{041 B}$ and $t_{052 B}$ denote loading part $\mathrm{B}$ to $p_{4}$ and $p_{5}$, respectively, where $R o_{2}$ is needed; $t_{420 B}$ and $t_{520 B}$ denote transporting part $\mathrm{B}$ to $p_{2}$, where $R o_{1}$ is needed; these operations can be done by common place $p_{r}$.

Step 3: Add the knowledge function of transitions based on a new machine 


$$
\begin{aligned}
& t_{041 B}=\Psi\left(p_{0}, p_{r}, c_{p 2}, c_{t 2}, d_{041 B}\right) \\
& t_{052 B}=\Psi\left(p_{o}, p_{r}, c_{p 2}, c_{t 2}, d_{052 B}\right) \\
& t_{520 B}=\Psi\left(p_{4}, p_{r}, c_{p 3}, c_{t 1}, d_{520 B}\right)
\end{aligned}
$$

An ICTPN for the reconfigured system with the addition of a new machine is shown in Figure 5.

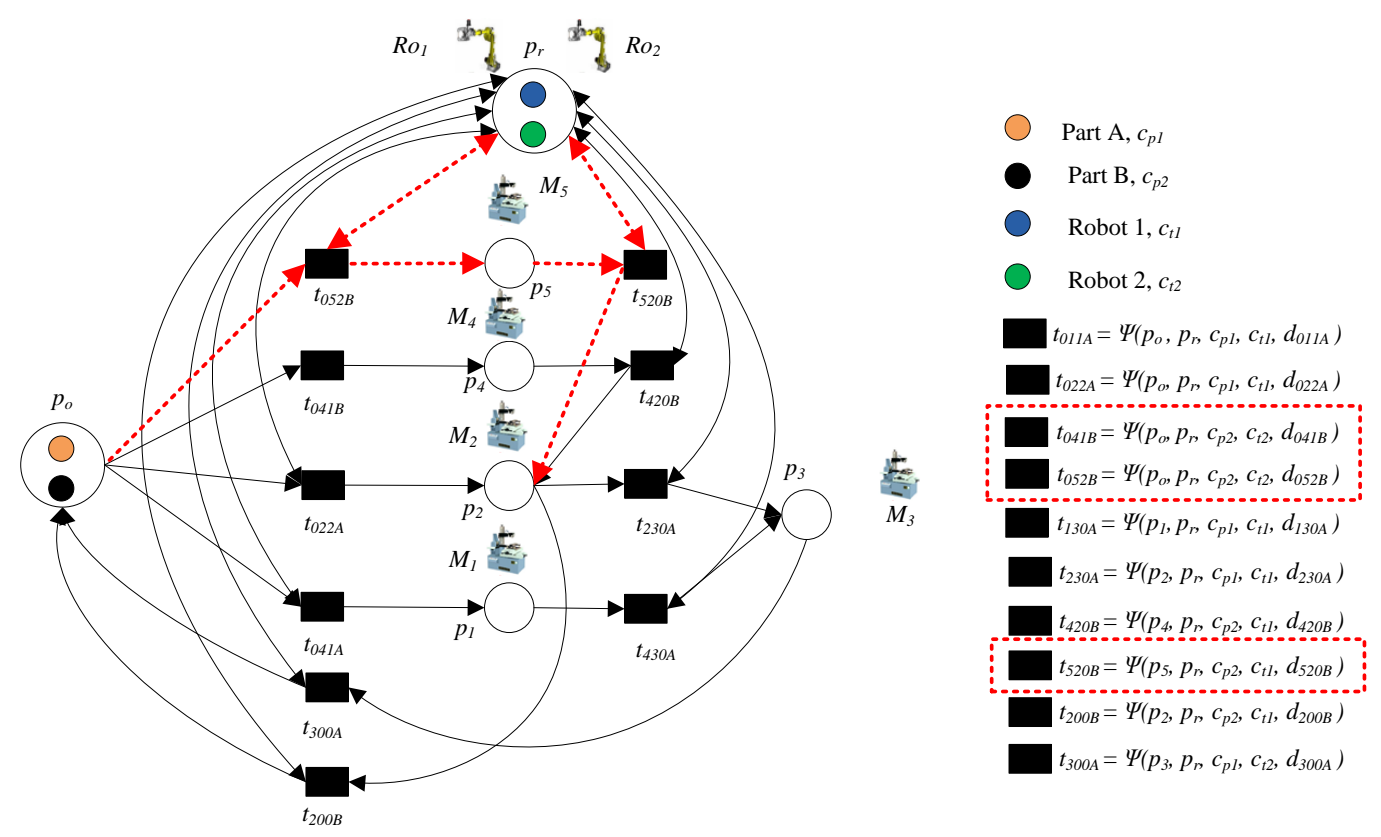

Figure 5. An ICTPN for the reconfigured system by addition of a new machine.

\subsection{Removal of Old Machine}

The fourth system reconfiguration includes the removal of an old machine. This indicates that the operations that use the removed machine need to be performed by another machine. Thus, some processing routes are changed, which implies a modification to the structure of its Petri net model. Reconsider the ICTPN model shown in Figure 2. Assume that machine $1 p_{1}$ is removed from the system, and $p_{2}$ will perform the operations that are previously performed by itself and performed by $p_{1}$. Therefore, the structure of the ICTPN model is changed and will be re-designed, such that the system with the removal of machine $p_{1}$ can operate continuously without stoppage. Hence, to model the reconfigured system, consider the following procedures:

Step 1: Delete all the transitions connected to the place corresponding to the removed machine $p_{1}$ and remove this place $p_{1}$.

Step 2: One operation route will be considered, which is $p_{0} \rightarrow t_{020 \mathrm{~A}} \rightarrow p_{2} \rightarrow t_{230 \mathrm{~A}}$ $\rightarrow p_{3} \rightarrow t_{300 A} \rightarrow p_{0}$.

Step 3: Delete the old knowledge function of transitions based on removed machine $p_{1}$.

$$
\begin{aligned}
& t_{011 A}=\Psi\left(p_{0}, p_{r}, c_{p 1}, c_{t 1}, d_{011 A}\right) \\
& t_{130 A}=\Psi\left(p_{4}, p_{r}, c_{p 1}, c_{t 1}, d_{130 A}\right)
\end{aligned}
$$

An ICTPN for the reconfigured system by removal of an old machine is shown in Figure 6. 


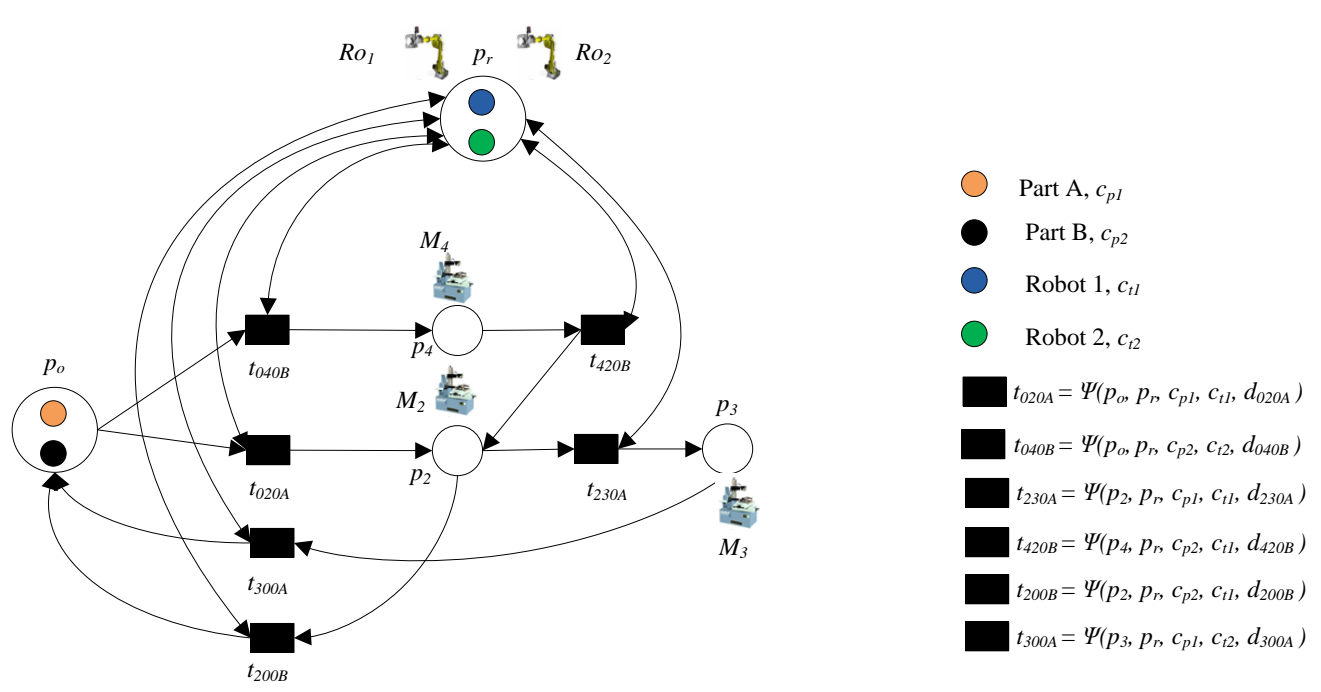

Figure 6. An ICTPN for the reconfigured system by removal of an old machine.

\subsection{Change Processing Routes}

The fifth system reconfiguration includes the change of processing routes. In this case, processing routes of parts are changed in the system, which implies a modification of the structure of its Petri net model. Reconsidering the ICTPN model shown in Figure 2, assume that the processing route of part A changes from $p_{0} \rightarrow p_{1} \rightarrow p_{3} \rightarrow p_{0}$, or $p_{0} \rightarrow p_{2} \rightarrow p_{3} \rightarrow p_{0}$ to $p_{0} \rightarrow p_{4} \rightarrow p_{3} \rightarrow p_{0}$, or $p_{0} \rightarrow p_{2} \rightarrow p_{3} \rightarrow p_{0}$, and the processing route of part $\mathrm{B}$ changes from $p_{0} \rightarrow p_{4} \rightarrow p_{2} \rightarrow p_{0}$ to $p_{0} \rightarrow p_{1} \rightarrow p_{2} \rightarrow p_{0}$. Therefore, the structure of the ICTPN model is changed and redesigned, such that the system works with changed processing routes. Hence, to model the reconfigured system, consider the following procedures:

Step 1: Change the names of transitions based on processing routes.

Step 2: Change the operation route of part A from $p_{0} \rightarrow t_{011 A} \rightarrow p_{1} \rightarrow t_{130 A} \rightarrow p_{3} \rightarrow t_{300 A} \rightarrow p_{0}$ to $p_{0} \rightarrow t_{041 \mathrm{~A}} \rightarrow p_{4} \rightarrow t_{430 \mathrm{~A}} \rightarrow p_{3} \rightarrow t_{300 \mathrm{~A}} \rightarrow p_{0}$.

Step 3: Change the operation route of part A from $p_{0} \rightarrow t_{040 B} \rightarrow p_{4} \rightarrow t_{420 B} \rightarrow p_{2} \rightarrow t_{200 B} \rightarrow p_{0}$ to $p_{0} \rightarrow t_{010 \mathrm{~B}} \rightarrow p_{1} \rightarrow t_{120 \mathrm{~B}} \rightarrow p_{2} \rightarrow t_{200 \mathrm{~B}} \rightarrow p_{0}$.

Step 4: Update the knowledge function of transitions based on removed machine $p_{1}$.

$$
\begin{aligned}
& t_{041 A}=\Psi\left(p_{0}, p_{r}, c_{p 1}, c_{t 1}, d_{041 A}\right) \\
& t_{430 A}=\Psi\left(p_{4}, p_{r}, c_{p 1}, c_{t 1}, d_{430 A}\right) \\
& t_{010 B}=\Psi\left(p_{o}, p_{r}, c_{p 1}, c_{t 2}, d_{010 B}\right) \\
& t_{120 B}=\Psi\left(p_{1}, p_{r}, c_{p 2}, c_{t 1}, d_{120 B}\right)
\end{aligned}
$$

An ICTPN for the reconfigured system by the removal of an old machine is shown in Figure 7. 


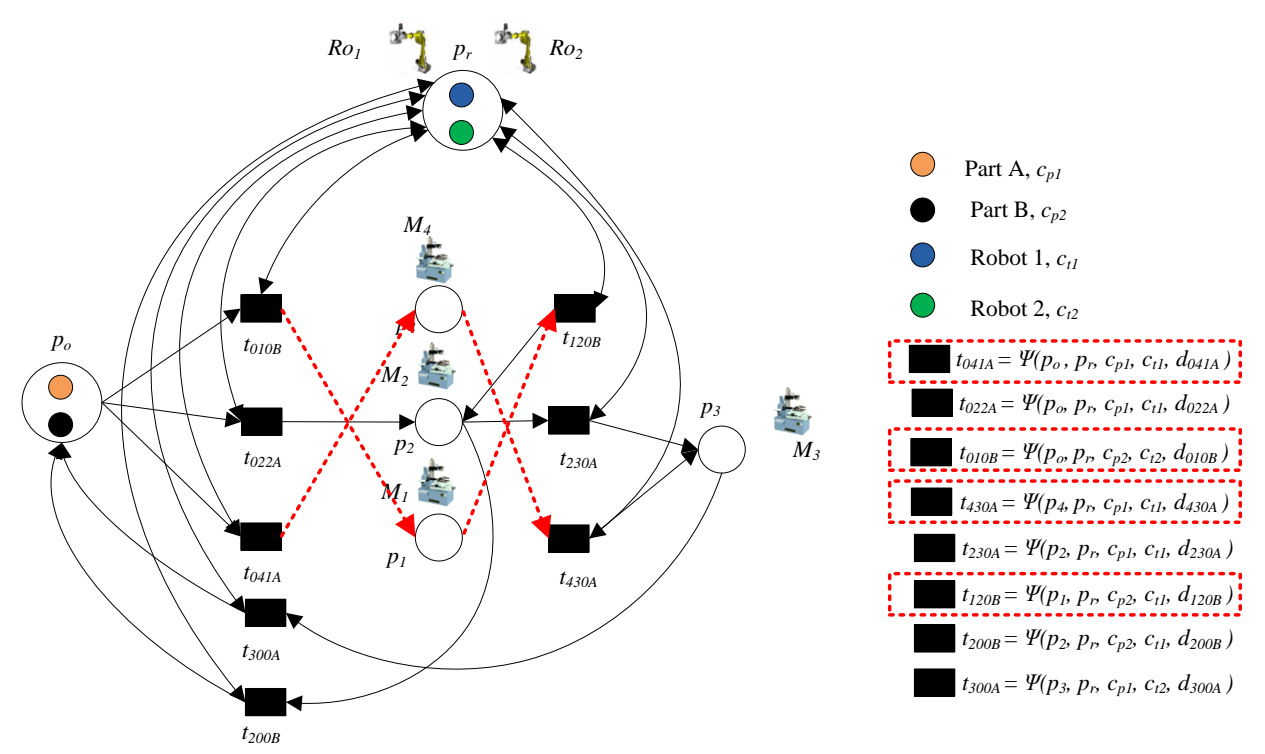

Figure 7. An ICTPN for the reconfigured system by removal of an old machine.

\subsection{Rework}

The sixth system reconfiguration includes rework. In this case, a part may be inspected when some of its operations are finished. If the reconfiguration is performed properly, then the system will continue based on an original route. Otherwise, rework is required. By using an ICTPN, the manufacturing operations of the reworked part can be easily and exactly modeled by considering rework operations as alternative routes. Reconsider the ICTPN model shown in Figure 2. Assume that $M_{3}$ is an inspection machine and that part $\mathrm{A}$ is processed in $M_{1}$ or $M_{2}$. Then, part $\mathrm{A}$ is transported to an inspection machine $M_{3}$ by Robot 1 to determine if there are defects in part $\mathrm{A}$. If part A performs properly, then it will depart the system by Robot 2. Otherwise, if part A has defects, rework is required, and part $\mathrm{A}$ is removed and transported to $M_{1}$ by Robot 2. Thus, part A has four possible routes:

1. Load-unload station $\rightarrow M_{1} \rightarrow$ inspection machine $M_{3} \rightarrow$ load-unload station,

2. Load-unload station $\rightarrow M_{2} \rightarrow$ inspection machine $M_{3} \rightarrow$ load-unload station,

3. Load-unload station $\rightarrow M_{1} \rightarrow$ inspection machine $M_{3} \rightarrow M_{1} \rightarrow$ inspection machine $\mathrm{M}_{3} \rightarrow$ load-unload station, or

4. Load-unload station $\rightarrow M_{2} \rightarrow$ inspection machine $M_{3} \rightarrow M_{1} \rightarrow$ inspection machine $M_{3} \rightarrow$ load-unload station.

Therefore, to model two routes by using the ICTPN synthesis procedure, a new transition can be added based on the original ICTPN. Hence, to model the reconfigured system, consider the following procedures:

Step 1: Add the process routes of part B as route 1: $p_{0} \rightarrow t_{011 A} \rightarrow p_{1} \rightarrow t_{130 A} \rightarrow p_{3} \rightarrow t_{300 A} \rightarrow p_{0}$, route $2: p_{0} \rightarrow t_{022 \mathrm{~A}} \rightarrow p_{2} \rightarrow t_{230 \mathrm{~A}} \rightarrow p_{3} \rightarrow t_{300 \mathrm{~A}} \rightarrow p_{0}$, route $3: p_{0} \rightarrow t_{011 \mathrm{~A}} \rightarrow p_{1} \rightarrow t_{130 \mathrm{~A}} \rightarrow p_{3} \rightarrow$ $t_{310 A} \rightarrow p_{1} \rightarrow t_{130 A} \rightarrow p_{3} \rightarrow t_{300 A} \rightarrow p_{0}$, or route $4: p_{0} \rightarrow t_{022 A} \rightarrow p_{1} \rightarrow t_{230 A} \rightarrow p_{3} \rightarrow t_{310 A} \rightarrow p_{1} \rightarrow$ $t_{130 \mathrm{~A}} \rightarrow p_{3} \rightarrow t_{300 \mathrm{~A}} \rightarrow p_{0}$.

Step 2: Add the knowledge function of transition based on rework:

$$
T_{310 A}=\Psi\left(p_{3}, p_{r}, c_{p 1}, c_{t 2}, d_{310 B}\right)
$$

An ICTPN for the reconfigured system by rework is shown in Figure 8. 


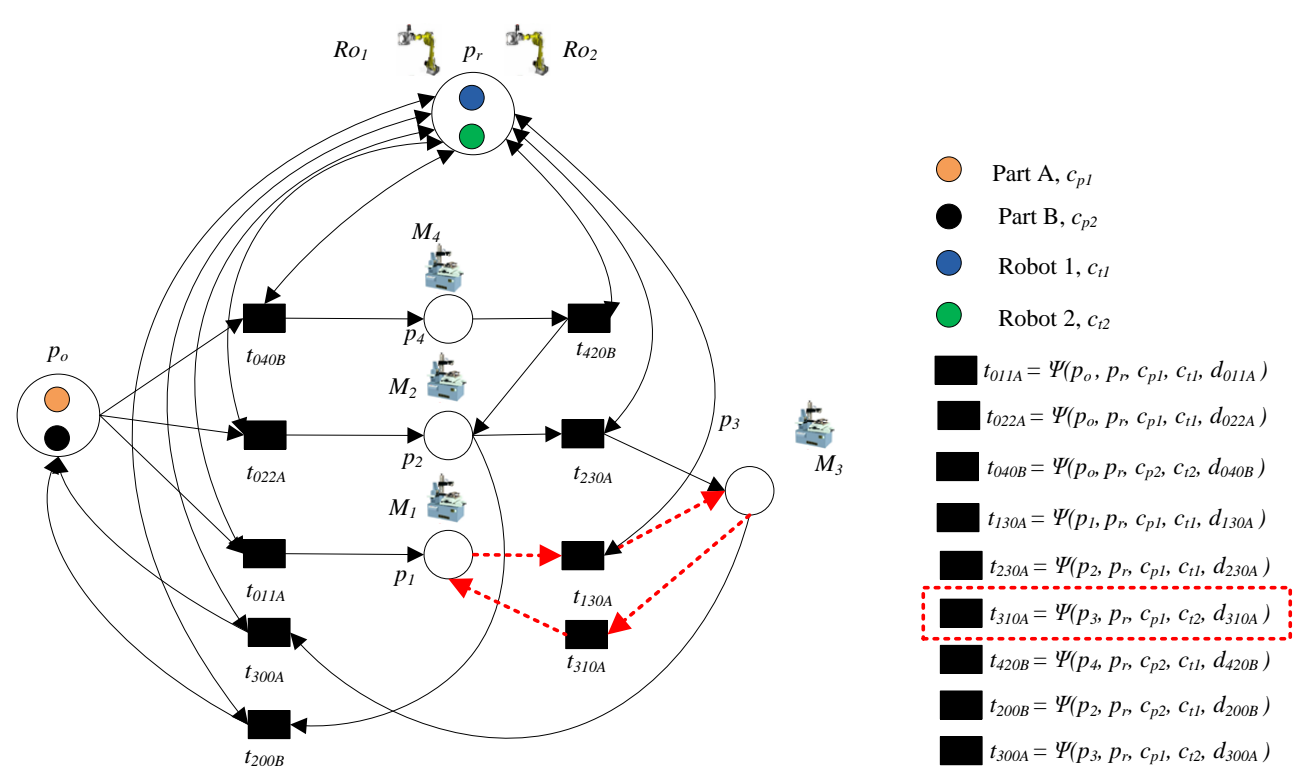

Figure 8. An ICTPN for the reconfigured system by rework.

\section{Qualitative and Quantitative Study of ICTPN}

\subsection{Deadlock}

A deadlock is a situation in which each process in a set of processes enters a waiting state because a requested resource is being held by another waiting process, which in turn is waiting for another resource. Thus, deadlocks should be avoided or prevented.

Theorem 1. The ICTPN is an intelligent colored token Petri net with $N=\left(P_{A} \cup\left\{p_{0}\right\} \cup\left\{p_{r}\right\}, T, F, W, M_{0}, K\right.$, and $\left.\Psi\left(p, c_{p i}, c_{t i}, d\right)\right)$, and is deadlock-free (live).

Proof. There is a need to prove that all transitions $T$ in the ICTPN are live. It does not matter how the system changes. For all $t \in T$, if $\forall p_{i} \in{ }^{\bullet} t$ and $M_{C}\left(p_{i}\right)>0$, then $t$ can fire in any case because it is uncontrollable.

To demonstrate the liveness of an ICTPN, consider the ICTPN model shown in Figure 2. Figure 9 shows the reachability graph of the ICTPN, and the system is live.
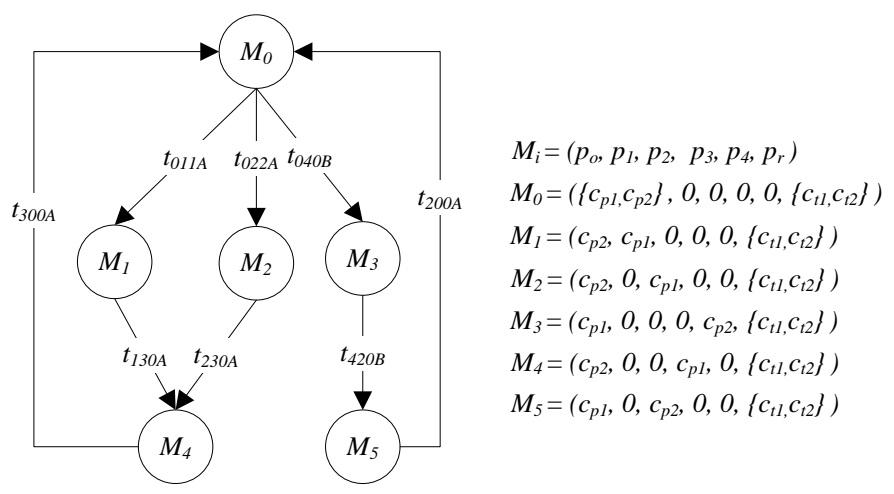

Figure 9. Reachable marking of an ICTPN example, as shown in Figure 2.

\subsection{Conservativeness}

Conservativeness is one of the main characteristics of ICTPN, where a transition, $t$, has one input place and one output place in $p_{r}$, i.e., ||$^{\bullet} \cap\left\{p_{r}\right\}|=| t^{\bullet} \cap\left\{p_{r}\right\} \mid=1$, and one input place and one output place 
in $P_{A}$, i.e., ||$^{\bullet} t \cap P_{A}|=| t^{\bullet} \cap P_{A} \mid=1$. Therefore, in the incidence matrix $D$ for an ICTPN, there is one -1 and one 1 in each row. Thus, if $y=(1,1, \ldots, 1)^{\mathrm{T}}, D y=\mathbf{0}$ must hold. For instance, reconsider the ICTPN model shown in Figure 2. We have $P=\left(p_{0}, p_{1}, p_{2}, p_{3}, p_{4}, p_{r}\right)$ and $T=\left(t_{011 A}, t_{022 A}, t_{040 B}, t_{130 A}, t_{230 A}, t_{420 B}\right.$, $\left.t_{200 B}, t_{300 A}\right)$. The incidence matrix $D$ of ICTPN model shown in Figure 2 is stated as follows:

$$
D=\left|\begin{array}{cccccc}
-1 & 0 & 1 & 0 & 0 & 0 \\
-1 & 0 & 0 & 1 & 0 & 0 \\
-1 & 0 & 0 & 0 & 0 & 1 \\
0 & 0 & -1 & 0 & 1 & 0 \\
0 & 0 & 0 & -1 & 1 & 0 \\
0 & 0 & 0 & 1 & 0 & -1 \\
1 & 0 & 0 & -1 & 0 & 0 \\
1 & 0 & 0 & 0 & -1 & 0
\end{array}\right|
$$

Thus, $D y=\mathbf{0}$ is satisfied with $y=(1,1,1,1,1,1)^{\mathrm{T}}$

$$
\left|\begin{array}{cccccc}
-1 & 0 & 1 & 0 & 0 & 0 \\
-1 & 0 & 0 & 1 & 0 & 0 \\
-1 & 0 & 0 & 0 & 0 & 1 \\
0 & 0 & -1 & 0 & 1 & 0 \\
0 & 0 & 0 & -1 & 1 & 0 \\
0 & 0 & 0 & 1 & 0 & -1 \\
1 & 0 & 0 & -1 & 0 & 0 \\
1 & 0 & 0 & 0 & -1 & 0
\end{array}\right| \times\left|\begin{array}{c}
1 \\
1 \\
1 \\
1 \\
1 \\
1
\end{array}\right|=\left|\begin{array}{c}
0 \\
0 \\
0 \\
0 \\
0 \\
0
\end{array}\right|
$$

\subsection{Reversibility}

An ICTPN is reversible if its initial marking can be reached from any other reachable marking.

Theorem 2. Assume that: (1) in an I CTPN, any part type has at least a route $R_{0} \rightarrow R_{1} \rightarrow R_{2} \rightarrow R_{3} \ldots \ldots$ $\rightarrow R_{n} \rightarrow R_{o}$ to complete it, and (2) after any reconfiguration, assumption 1 is still met. Then, the ICTPN that builds the configurations of the system is reversible.

Proof. The dynamic changes in an AMS can be effectively constructed by an ICTPN, and the system can be controlled to be reversible if the suppositions given in Theorem 2 are met. Suppositions 1 and 2 ensure that for any $c_{p i}$, there is at least a route $R_{o} \rightarrow R_{1} \rightarrow R_{2} \rightarrow R_{3} \ldots \ldots \rightarrow R_{n} \rightarrow R_{o}$ that starts from $p_{0}$, moves through some operation places other than $p_{0}$, and ends at $p_{0}$. It does not matter how the system is modified. Hence, the operation places can always be unmarked or are reversible.

To demonstrate the reachability of an ICTPN, consider the ICTPN model shown in Figure 2. Figure 9 shows the reachability graph of the ICTPN, and the system is reversible.

\subsection{Structural Complexity}

The structural complexity depends on the fact that Algorithm 1 can model an ICTPN $N=\left(P_{A}\right.$ $\cup\left\{p_{o}\right\} \cup\left\{p_{r}\right\}, T, F, W, M_{o}, K$, and $\left.\Psi\left(p, c_{p i}, c_{t i}, d\right)\right)$ with fewer places, transitions, and arcs, which leads to a decrease in software and hardware costs. First, we compare the results of the ICTPN model of Figure 2 with the traditional PN methods in the studies of Chen et al. [33], Piroddi et al. [34], Chen and Li [35], Chen et al. [36], and Kaid et al. [37]. Table 1 lists the results for the numbers of idle process places, operation places, resource places, transportation places, transitions, monitors, arcs, as well as liveness, and reachable markings. We observe that the proposed ICTPN model is minimal compared with other techniques used by Chen et al. [33], Piroddi et al. [34], Chen and Li [35], Chen et al. [36], and Kaid et al. [37]. 
Table 1. Structural complexity comparison with the existing policies.

\begin{tabular}{ccccccc}
\hline Parameters & $\begin{array}{c}\text { Chen } \\
\text { et al. [33] }\end{array}$ & $\begin{array}{c}\text { Piroddi } \\
\text { et al. [34] }\end{array}$ & $\begin{array}{c}\text { Chen and } \\
\text { Li [35] }\end{array}$ & $\begin{array}{c}\text { Chen } \\
\text { et al. [36] }\end{array}$ & $\begin{array}{c}\text { Kaid } \\
\text { et al. [37] }\end{array}$ & $\begin{array}{c}\text { Proposed } \\
\text { ICTPN Model }\end{array}$ \\
\hline No. idle process places & 2 & 2 & 2 & 2 & 2 & 1 \\
No. operation places & 12 & 12 & 12 & 12 & 12 & 4 \\
No. resource places & 4 & 4 & 4 & 4 & 4 & 0 \\
No. transportation & 2 & 2 & 2 & 2 & 2 & 1 \\
places & 14 & 14 & 14 & 14 & 14 & 8 \\
No. transitions & 8 & 5 & 2 & 2 & 1 & 0 \\
Monitors & 37 & 23 & 12 & 12 & 9 & 0 \\
Arcs & Live & Live & Live & Live & Live & Live \\
Liveness & 205 & 205 & 205 & 205 & 205 & 6 \\
Reachable marking & & & & & &
\end{tabular}

\subsection{Validation and Behavioral Permissiveness of ICTPN Model}

To test and validate the developed ICTPN model, we coded an ICTPN model using the GPenSIM tool [37,38], and the code is validated and compared with Chen et al. [33], Piroddi et al. [34], Chen and Li [35], Chen et al. [36], and Kaid et al. [37]. We created three files: (1) the Petri net definition file (PDF), which defines the static ICTPN model by declaring the sets of places, transitions, and arcs, (2) the common processor file (COMMON_PRE file), which defines the conditions for the enabled transitions to start firing based on the intelligent colored tokens, and (3) the main simulation file (MSF) to compute the simulation results. The GPenSIM code was also built in MATLAB.

Behavioral permissiveness leads to the better time performance in an ICTPN, such as utilization of the robots and machines, total throughput, work-in-process (WIP), and total time in system (throughput time). The simulation was undertaken for $480 \mathrm{~min}$. After running and simulating the ICTPN model in MATLAB, we obtained the results summarized in Table 2. Table 2 illustrates the results in terms of the aforementioned time performance criteria. In terms of the resource utilization, overall, the proposed model can obtain better utilization than the other techniques, as illustrated in Figure 10. Moreover, from the viewpoint the throughput, the proposed model can provide greater throughput than the other techniques, as illustrated in Figure 11. With respect to the throughput time per part, the proposed model can obtain less throughput time than other techniques, as illustrated in Figure 12. Finally, in terms of WIP, the proposed model leads to better WIP than the other techniques, as illustrated in Figure 13.

Table 2. Time performance comparison with the existing policies.

\begin{tabular}{|c|c|c|c|c|c|c|}
\hline Parameter & $\begin{array}{c}\text { Chen } \\
\text { et al. [33] }\end{array}$ & $\begin{array}{l}\text { Piroddi } \\
\text { et al. [34] }\end{array}$ & $\begin{array}{l}\text { Chen and } \\
\text { Li [35] }\end{array}$ & $\begin{array}{c}\text { Chen } \\
\text { et al. [36] }\end{array}$ & $\begin{array}{c}\text { Kaid } \\
\text { et al. [37] }\end{array}$ & $\begin{array}{c}\text { Proposed } \\
\text { ICTPN Model }\end{array}$ \\
\hline M 1 utilization \% & 18.75 & 17.7083 & 17.7083 & 17.7083 & 17.7083 & 30.625 \\
\hline M 2 utilization \% & 35 & 33.3333 & 33.3333 & 33.3333 & 33.9583 & 36.4583 \\
\hline M 3 utilization $\%$ & 12.5 & 13.75 & 14.375 & 14.375 & 12.5 & 51.25 \\
\hline M 4 utilization $\%$ & 22.5 & 21.6667 & 20.8333 & 20.8333 & 22.5 & 15 \\
\hline R 1 utilization $\%$ & 39.5833 & 40 & 40.4167 & 40.4167 & 39.5833 & 44.583 \\
\hline R 2 utilization $\%$ & 29.375 & 30 & 30 & 30 & 30 & 61.25 \\
\hline Total throughput of Parts & 46 & 46 & 46 & 46 & 47 & 49 \\
\hline Work-In-Process & 3.9271 & 3.93331 & 3.8480 & 3.9667 & 3.3854 & 3.31222 \\
\hline Throughput time per part (min) & 10.3321 & 10.2325 & 10.5554 & 10.6635 & 10.2127 & 9.7959 \\
\hline
\end{tabular}




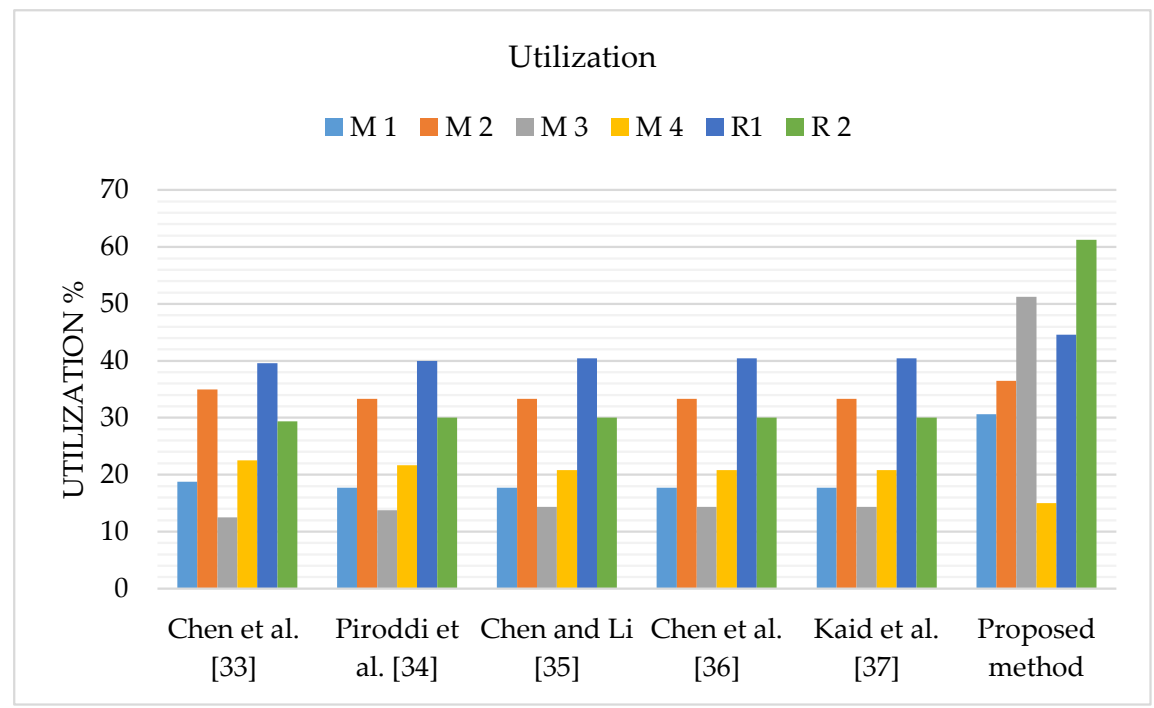

Figure 10. Comparison of utilization for the Petri net model in Figure 2.

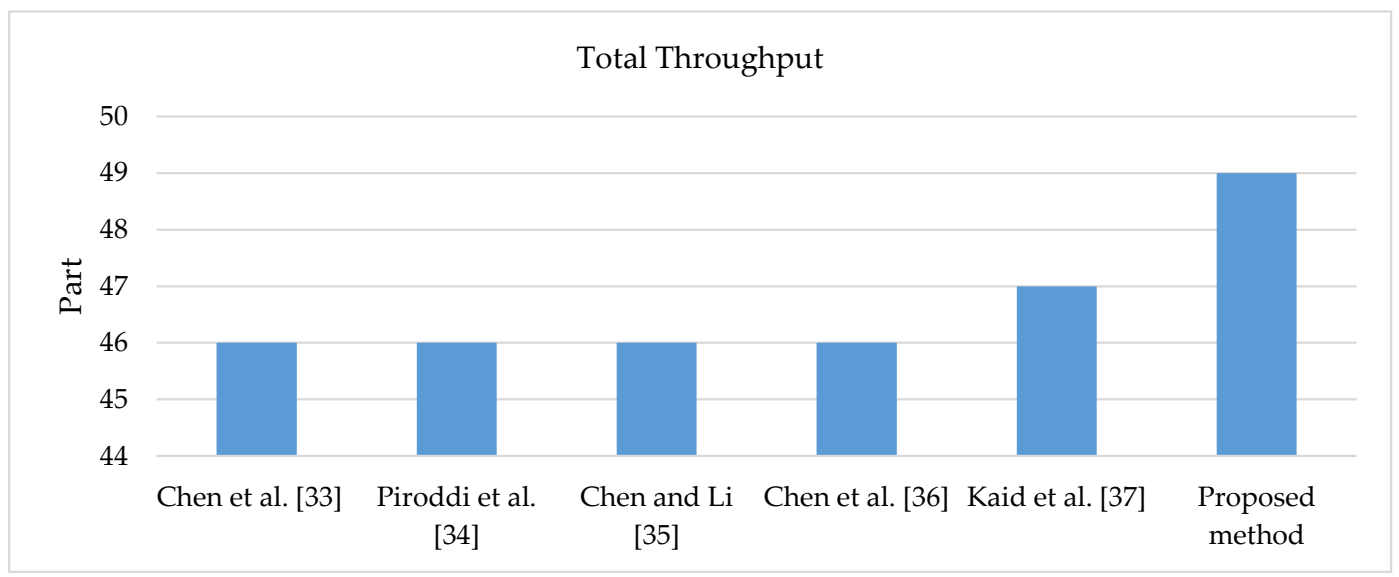

Figure 11. Comparison of throughput for the Petri net model in Figure 2.

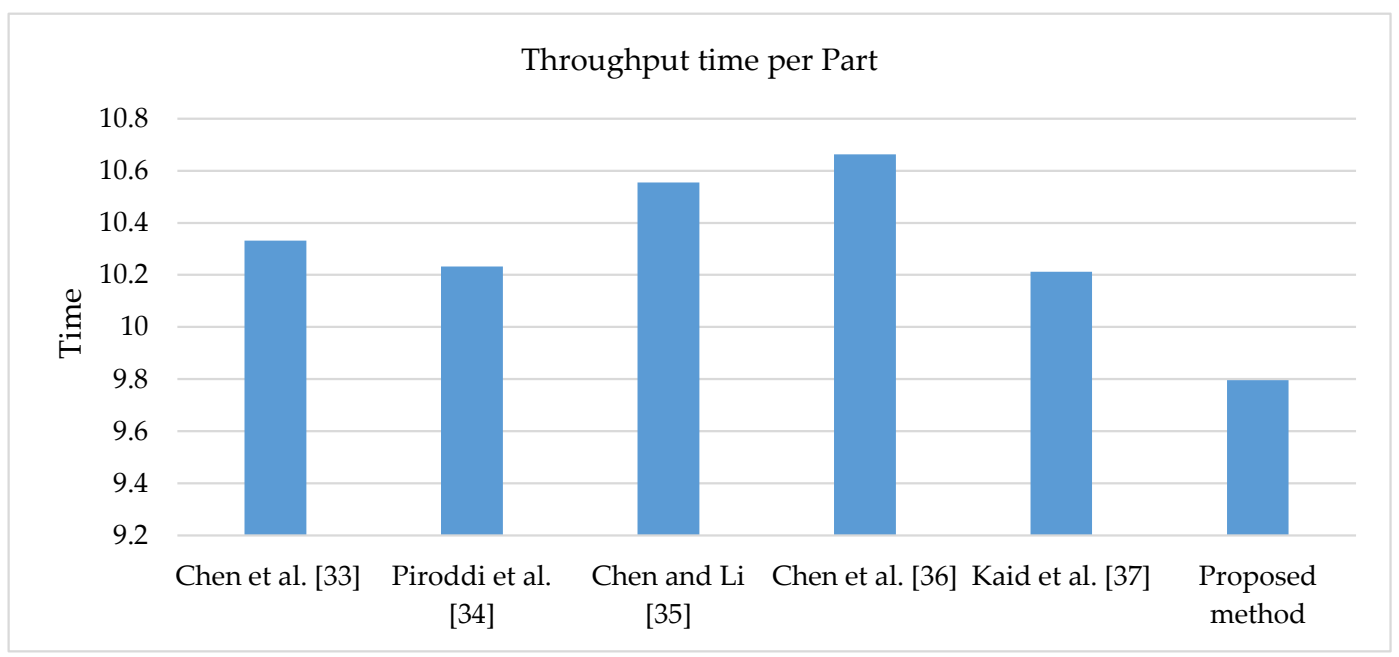

Figure 12. Comparison of the throughput time per part for the Petri net model in Figure 2. 


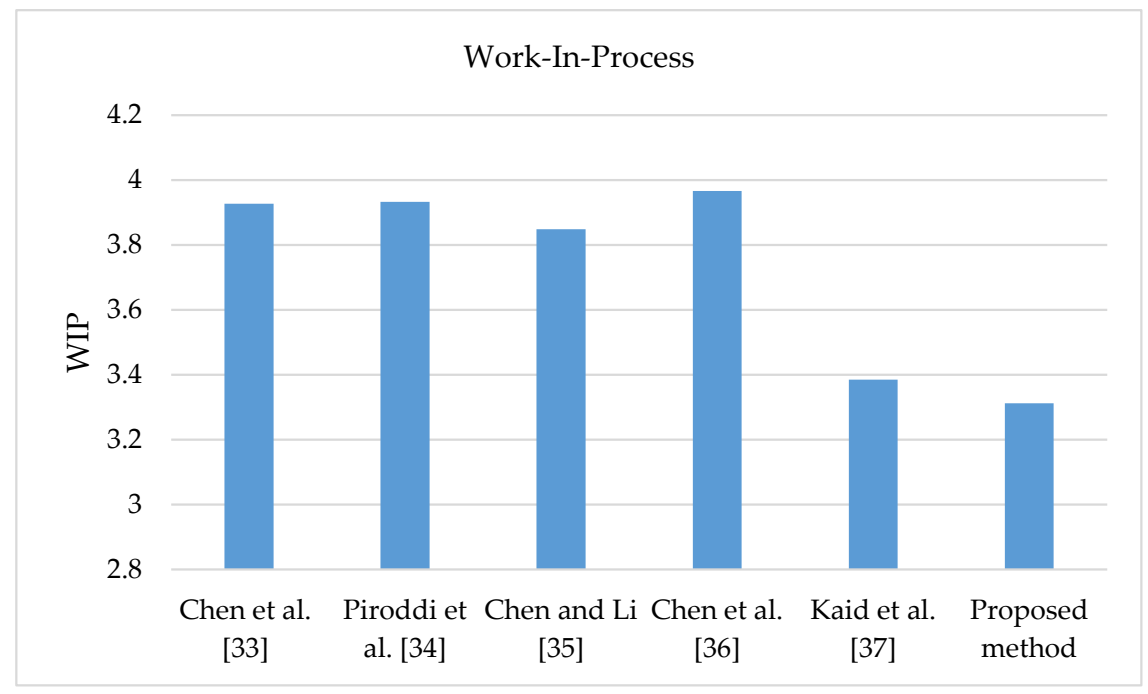

Figure 13. Comparison of WIP for the Petri net model in Figure 2.

\subsection{Computational Complexity}

Algorithm 1 models an ICTPN with $N=\left(P_{A} \cup\left\{p_{o}\right\} \cup\left\{p_{r}\right\}, T, F, W, M_{o}, K, \Psi\left(p, c_{p i}, c_{t i}, d\right)\right)$. Algorithm 1 is used to model the operation and transportation resources and initial marking of the ICTPN. Obviously, all possible routes $O R=\left\{O R_{1}, O R_{2}, O R_{3}, \ldots, O R_{n}\right\}$ in a system for all types of parts are modeled. Based on the fact that each route $O R$ in a system has $R_{o} \rightarrow R_{i 1} \rightarrow R_{i 2} \rightarrow \ldots \ldots \rightarrow R_{i F i} \rightarrow R_{o}$. Each sub-route $R$ requires place $p_{a}$ that corresponds to $R_{i(j-1)}$, place $p_{a}$ that corresponds to $R_{i j}$, and transition $t$, an arc from $p_{a}$ to $t$, an arc from $t$ to $p_{b}$, an arc from common place $p_{r}$ to $t$, and an arc from $t$ to common place $p_{r}$. Note that one common transportation resource $p_{r}$ is added and represents all transportation resources in the system. Therefore, let $x$ be the number of possible routes, $O R$, i.e., $|O R|=x$. The number of each sub-route $F_{i}$ is expressed by $y$, i.e., $\left|F_{i}\right|=y$. The number of corresponding places, transitions, and arcs to each sub-route is expressed by $I$, i.e., $|I|=z$. The number of transportation resources $p_{r}$ is 1, i.e., $\left|p_{r}\right|=1$. The "FOR loop" is executed ( $\left.x y z\right)$ times to model an ICTPN. Thus, the computational complexity is $\mathbf{O}(x y z)$. In the proposed algorithm by Wu and Zhou [6], all transportation resources are required to be added; thus, the number of transportation resources $p_{r i}$ is expressed as $k$, i.e., $\left|p_{r i}\right|=k$. Therefore, the computational complexity of the proposed algorithm in the study of $\mathrm{Wu}$ and Zhou [6] is $\mathbf{O}(x y z+k)$. Thus, Algorithm 1 has minimal computational complexity compared with that of $\mathrm{Wu}$ and Zhou [6] and can be implemented in a large-scale system. In fact, Algorithm 1 has polynomial time complexity.

\section{Conclusions}

This paper presented a new model named an intelligent colored token Petri net for automatic reconfiguration of RMS to face the dynamical changes in the manufacturing system. The main idea is that intelligent colored tokens denote product types that represent real-time knowledge about changes and status of a system. Thus, dynamical configurations of a system can be effectively modelled. The developed ICTPN can model dynamical changes of a system in a modular manner, resulting in an easily compact model. In addition, when configurations appear, only the changed colored token from the current model has to be modified. The developed ICTPN model was tested and validated using the GPenSIM tool and compared with the existing methods from the literature.

The main advantages of the proposed method are: (1) The proposed ICTPN model is more powerful, has a simpler structure, does not need to calculate reachability graphs, and has low-overhead computation compared with Chen et al. [33], Piroddi et al. [34], Chen and Li [35], Chen et al. [36], and Kaid et al. [37]. (2) It can easily handle any dynamical changes in RMS compared with Lee and Tilbury [4], Li et al. [5], and Wu and Zhou [6]. (3) It can obtain one common transportation resource 
place to transport all part types compared with $\mathrm{Wu}$ and Zhou [6]. (4) GPenSIM code is developed for simulation, validation, and performance comparison compared with $\mathrm{Li}$ et al. [5], and $\mathrm{Wu}$ and Zhou [6]. (5) The proposed ICTPN model can dynamically change the structure of a PN without damaging its behavioral properties, i.e., liveness, conservativeness, boundedness, and reversibility. (6) We provided a representation of a RMS configuration and presented an ICTPN model for designing a modular. (7) The proposed ICTPN model can be applicable to other types of complex AMSs such as semiconductor fabrication system and liquid-crystal display factory, including automated storage and retrieval systems, automated guided vehicle, and machines. (8) The proposed ICTPN model can consider systems with sequential and complex resource requirements.

The main limitation of the proposed method is that the the ICTPN model lacks an efficient conversion method from the ICTPN model into industrial control languages for application. Therefore, our future research will investigate the proposed model to have an automatic way to test the applicability of the ICTPN model for real world systems. It is crucial to come up with a means to convert the ICTPN model into ladder diagrams (LDs) for implementation on programmable logic controllers (PLCs) [24], using adaptive control techniques [39], or using surveillance systems [40]. We will also consider to model and schedule automated manufacturing systems [41] and social networks [42] using the proposed model methodology.

Author Contributions: Conceptualization, H.K. and A.A.-A.; software, H.K. and R.D.; resources, H.K., A.A.-A. and R.D.; formal analysis, H.K. and A.A.-A.; investigation, H.K., A.A.-A. and Z.L.; validation, H.K., A.A.-A., Z.L. and R.D.; writing —original draft preparation, H.K., A.A.-A. and Z.L.; writing-review and editing, H.K., A.A.-A., Z.L. and R.D.; visualization, H.K., A.A.-A. and Z.L.; supervision, A.A.-A., and Z.L. All authors have read and agreed to the published version of the manuscript.

Funding: This research was funded by King Saud University, grant number (RSP-2019/62), and the APC was funded by King Saud University.

Acknowledgments: The authors would like to thank King Saud University for funding and supporting this research through Researchers Supporting Project Number (RSP-2019/62).

Conflicts of Interest: The authors declare no conflict of interest.

\section{References}

1. Mehrabi, M.G.; Ulsoy, A.G.; Koren, Y. Reconfigurable manufacturing systems: Key to future manufacturing. J. Intell. Manuf. 2000, 11, 403-419. [CrossRef]

2. Katz, R. Design principles of reconfigurable machines. Int. J. Adv. Manuf. Technol. 2007, 34, 430-439. [CrossRef]

3. Patel, R.; Gojiya, A.; Deb, D. Failure reconfiguration of pumps in two reservoirs connected to overhead tank. In Innovations in Infrastructure; Springer: Berlin/Heidelberg, Germany, 2019; pp. 81-92.

4. Lee, S.; Tilbury, D.M. Deadlock-free resource allocation control for a reconfigurable manufacturing system with serial and parallel configuration. IEEE Trans. Syst. Man Cybern. Part C (Appl. Rev.) 2007, 37, 1373-1381. [CrossRef]

5. Li, J.; Dai, X.; Meng, Z. Automatic reconfiguration of petri net controllers for reconfigurable manufacturing systems with an improved net rewriting system-based approach. IEEE Trans. Autom. Sci. Eng. 2009, 6, 156-167. [CrossRef]

6. Wu, N.; Zhou, M. Intelligent token petri nets for modelling and control of reconfigurable automated manufacturing systems with dynamical changes. Trans. Inst. Meas. Control 2011, 33, 9-29.

7. Târnaucă, B.; Puiu, D.; Comnac, V.; Suciu, C. Modelling a flexible manufacturing system using reconfigurable finite capacity petri nets. In Proceedings of the 2012 13th International Conference on. Optimization of Electrical and Electronic Equipment (OPTIM), Brasov, Romania, 24-26 May 2012; pp. 1079-1084.

8. Kahloul, L.; Bourekkache, S.; Djouani, K.; Chaoui, A.; Kazar, O. Using high level petri nets in the modelling, simulation and verification of reconfigurable manufacturing systems. Int. J. Softw. Eng. Knowl. Eng. 2014, 24, 419-443. [CrossRef]

9. Berthomieu, B.; Ribet, P.-O.; Vernadat, F. The tool tina-construction of abstract state spaces for petri nets and time petri nets. Int. J. Prod. Res. 2004, 42, 2741-2756. [CrossRef] 
10. Bonet, P.; Catalina, M.L.; Puigjaner, R. A petri net tool for performance modeling. In Proceedings of the $23 \mathrm{rd}$ Latin American Conference on Informatics, San Jose, Costa Rica, 10-11 October 2007.

11. Da Silva, R.M.; Benítez-Pina, I.F.; Blos, M.F.; Santos Filho, D.J.; Miyagi, P.E. Modeling of reconfigurable distributed manufacturing control systems. IFAC Pap. 2015, 48, 1284-1289. [CrossRef]

12. Yu, Z.; Guo, F.; Ouyang, J.; Zhou, L. Object-oriented petri nets and $\pi$-calculus-based modeling and analysis of reconfigurable manufacturing systems. Adv. Mech. Eng. 2016, 8, 1687814016677698. [CrossRef]

13. Chao, D.Y. Fewer monitors and more efficient controllability for deadlock control in s3pgr2 (systems of simple sequential processes with general resource requirements). Comput. J. 2010, 53, 1783-1798. [CrossRef]

14. Chao, D.Y. Improvement of suboptimal siphon-and fbm-based control model of a well-known $\mathrm{s}^{3} \mathrm{pr}$. IEEE Trans. Autom. Sci. Eng. 2011, 8, 404-411. [CrossRef]

15. Li, Z.; Zhou, M. Elementary siphons of petri nets and their application to deadlock prevention in flexible manufacturing systems. Syst. Man Cybern. Part A Syst. Hum. IEEE Trans. 2004, 34, 38-51. [CrossRef]

16. Uzam, M. An optimal deadlock prevention policy for flexible manufacturing systems using petri net models with resources and the theory of regions. Int. J. Adv. Manuf. Technol. 2002, 19, 192-208. [CrossRef]

17. Uzam, M.; Zhou, M. Iterative synthesis of petri net based deadlock prevention policy for flexible manufacturing systems. In Proceedings of the 2004 IEEE International Conference on Systems, Man and Cybernetics, The Hague, The Netherlands, 10-13 October 2004; pp. 4260-4265.

18. Pan, Y.-L.; Tseng, C.-Y.; Row, T.-C. Design of improved optimal and suboptimal deadlock prevention for flexible manufacturing systems based on place invariant and reachability graph analysis methods. J. Algorithms Comput. Technol. 2017, 11, 261-270. [CrossRef]

19. Zhao, M.; Uzam, M. A suboptimal deadlock control policy for designing non-blocking supervisors in flexible manufacturing systems. Inf. Sci. 2017, 388, 135-153. [CrossRef]

20. Cong, X.; Gu, C.; Uzam, M.; Chen, Y.; Al-Ahmari, A.M.; Wu, N.; Zhou, M.; Li, Z. Design of optimal petri net supervisors for flexible manufacturing systems via weighted inhibitor arcs. Asian J. Control 2018, 20, 511-530. [CrossRef]

21. Abdulaziz, M.; Nasr, E.A.; Al-Ahmari, A.; Kaid, H.; Li, Z. Evaluation of deadlock control designs in automated manufacturing systems. In Proceedings of the 2015 International Conference on Industrial Engineering and Operations Management, Dubai, UAE, 3-5 March 2015.

22. Wang, S.; You, D.; Zhou, M. A necessary and sufficient condition for a resource subset to generate a strict minimal siphon in S 4PR. IEEE Trans. Autom. Control 2017, 62, 4173-4179. [CrossRef]

23. Zhuang, Q.; Dai, W.; Wang, S.; Du, J.; Tian, Q. An mip-based deadlock prevention policy for siphon control. IEEE Access 2019, 7, 153782-153790. [CrossRef]

24. Kaid, H.; Al-Ahmari, A.; El-Tamimi, A.M.; Abouel Nasr, E.; Li, Z. Design and implementation of deadlock control for automated manufacturing systems. S. Afr. J. Ind. Eng. 2019, 30, 1-23. [CrossRef]

25. Nasr, E.A.; El-Tamimi, A.M.; Al-Ahmari, A.; Kaid, H. Comparison and evaluation of deadlock prevention methods for different size automated manufacturing systems. Math. Probl. Eng. 2015, 501, 1-19. [CrossRef]

26. Sun, D.; Chen, Y.; El-Meligy, M.A.; Sharaf, M.A.F.; Wu, N.; Li, Z. On algebraic identification of critical states for deadlock control in automated manufacturing systems modeled with petri nets. IEEE Access 2019, 7, 121332-121349. [CrossRef]

27. Al-Ahmari, A.; Kaid, H.; Li, Z.; Davidrajuh, R. Strict minimal siphon-based colored petri net supervisor synthesis for automated manufacturing systems with unreliable resources. IEEE Access 2020, 8, 22411-22424. [CrossRef]

28. Li, L.; Basile, F.; Li, Z. An approach to improve permissiveness of supervisors for gmecs in time petri net systems. IEEE Trans. Autom. Control 2019, 65, 237-251. [CrossRef]

29. Liu, Y.; Cai, K.; Li, Z. On scalable supervisory control of multi-agent discrete-event systems. Automatica 2019, 108, 108460. [CrossRef]

30. Chen, Q.; Yin, L.; Wu, N.; El-Meligy, M.A.; Sharaf, M.A.F.; Li, Z. Diagnosability of vector discrete-event systems using predicates. IEEE Access 2019, 7, 147143-147155. [CrossRef]

31. Wang, D.; Wang, X.; Li, Z. Nonblocking supervisory control of state-tree structures with conditional-preemption matrices. IEEE Trans. Ind. Inform. 2019, 16, 3744-3756. [CrossRef]

32. Hu, Y.; Ma, Z.; Li, Z. Design of supervisors for active diagnosis in discrete event systems. IEEE Trans. Autom. Control 2020. [CrossRef] 
33. Chen, Y.; Li, Z.; Khalgui, M.; Mosbahi, O. Design of a maximally permissive liveness-enforcing petri net supervisor for flexible manufacturing systems. Autom. Sci. Eng. IEEE Trans. 2011, 8, 374-393. [CrossRef]

34. Piroddi, L.; Cordone, R.; Fumagalli, I. Selective siphon control for deadlock prevention in petri nets. Syst. Man Cybern. Part A Syst. Hum. IEEE Trans. 2008, 38, 1337-1348. [CrossRef]

35. Chen, Y.; Li, Z. Design of a maximally permissive liveness-enforcing supervisor with a compressed supervisory structure for flexible manufacturing systems. Automatica 2011, 47, 1028-1034. [CrossRef]

36. Chen, Y.; Li, Z.; Zhou, M. Behaviorally optimal and structurally simple liveness-enforcing supervisors of flexible manufacturing systems. Syst. Man Cybern. Part A Syst. Hum. IEEE Trans. 2012, 42, 615-629. [CrossRef]

37. Kaid, H.; Al-Ahmari, A.; Li, Z.; Davidrajuh, R. Single controller-based colored petri nets for deadlock control in automated manufacturing systems. Processes 2020, 8, 21. [CrossRef]

38. Davidrajuh, R. Modeling Discrete-Event Systems with Gpensim: An Introduction; Springer: Berlin/Heidelberg, Germany, 2018.

39. Tao, G. Adaptive Control Design and Analysis; John Wiley \& Sons: Hoboken, NJ, USA, 2003; Volume 37.

40. Upadhyay, J.; Deb, D.; Rawat, A. Design of smart door closer system with image classification over WLAN. Wirel. Pers. Commun. 2019, 111, 1941-1953. [CrossRef]

41. Zan, X.; Wu, Z.; Guo, C.; Yu, Z. A pareto-based genetic algorithm for multi-objective scheduling of automated manufacturing systems. Adv. Mech. Eng. 2020, 12, 1-15. [CrossRef]

42. Yang, L.; Li, Z.; Giua, A. Containment of rumor spread in complex social networks. Inf. Sci. 2020, 506, 113-130. [CrossRef]

(C) 2020 by the authors. Licensee MDPI, Basel, Switzerland. This article is an open access article distributed under the terms and conditions of the Creative Commons Attribution (CC BY) license (http://creativecommons.org/licenses/by/4.0/). 